\title{
The Best Years of Older Europeans' Lives
}

\author{
Begoña Álvarez ${ }^{1}$ (D)
}

Accepted: 16 September 2021 / Published online: 25 September 2021

(c) The Author(s) 2021

\begin{abstract}
This paper offers new evidence on the life-cycle pattern of happiness. A novelty of the analysis is that it exploits information on the period individuals recall as the happiest in their lives. Data come from SHARELIFE 2008/09, a retrospective life survey conducted in 13 European countries among individuals aged 50 or more. Using this information, I build a longitudinal data set that extends across the whole lifespan of respondents. The probability of living a happiest year in life at each age is estimated through a conditional fixed effects logit model. Results show that the likelihood of living the happiest period in life exhibits a concave relationship with age, with a turning point at about 30-34 years and a decreasing trend from that point onward. Retrospectively, midlife is not perceived as the least likely happiest period in life. These patterns persist even after controlling for usual correlates of subjective well-being, and they are rather stable across cohorts and genders despite presenting certain variability across European countries.
\end{abstract}

Keywords Subjective well-being $\cdot$ Retrospective data $\cdot$ Ageing $\cdot$ SHARELIFE

JEL classification $\mathrm{I} 31 \cdot \mathrm{J} 14 \cdot \mathrm{C} 81 \cdot \mathrm{N} 44$

\section{Introduction}

Evidence from psychology and behavioral economics shows that how we remember and assess the past-in terms of subjective well-being — does not necessarily coincide with the feelings and emotions we actually experienced (Kahneman \& Riis, 2005). This mismatch does not invalidate the informational content of our memories. In fact, some experiments reveal that our preferences and, therefore, our current choices and decisions to repeat

This paper uses data from SHARE wave 1 and 2 release 2.5.0 as of 24 May 2011, from SHARELIFE release 1 as of 24 November 2010, and from the generated Job Episodes Panel. (DOI: 10.6103/SHARE. jep.600), see Brugiavini et al. (2013) and Antonova et al. (2014) for methodological details. The Job Episodes Panel release 6.0.0 is based on SHARE Waves 1, 2 and 3 (SHARELIFE) (DOIs: 10.6103/ SHARE.w1.600, 10.6103/SHARE.w2.600, 10.6103/SHARE.w3.600). The SHARE data collection is funded mainly by the European Commission (see www.share-project.org for a full list of funding institutions).

Begoña Álvarez

alvarez@uvigo.es

1 Departamento de Economía Aplicada, Universidade de Vigo, 36310 Vigo, Spain 
events are more affected by the recalled utility associated with past experiences than by the utility experienced when we lived through these events (Kahneman \& Thaler, 2006; Kahneman et al., 1997; Oishi \& Sullivan, 2006; Pudney, 2011; Wirtz et al., 2003). According to this literature, retrospective assessments help us understand present decision-making and even disentangle why individuals may choose options that apparently do not maximize current well-being.

This paper examines the life-cycle pattern of subjective well-being that emerges when older individuals evaluate their lives retrospectively. Most of our knowledge on the relationship between subjective well-being (SWB from now on) and age builds on evaluative measures consisting of individuals' overall assessments of current levels of happiness or life satisfaction (see, for instance, reviews by López Ulloa et al., 2013; Blanchflower, 2020; Galambos et al., 2020). Although there is controversy over the degree to which results depend on the type of data used for the analysis (cross-sectional or longitudinal), the methodological approach or the functional form imposed in econometric specifications (mostly quadratic in age), the predominant finding is that the relationship between individual subjective well-being and age is U-shaped-at least until people reach their late $60 \mathrm{~s}$ (e.g. Blanchflower, 2020; Blanchflower \& Oswald, 2004, 2008; Cheng et al., 2017; Clark \& Oswald, 1994, 2006; Clark et al., 2020; Van Praag \& Ferrer-i-Carbonell, 2004). The minimum is achieved around mid-40 s or mid-50 s, though some heterogeneity in the exact age across social groups and countries is present (e.g., Blanchflower \& Oswald, 2008; Graham and Ruiz Pozuelo, 2017; Blanchflower, 2020; Clark et al., 2020). The nadir in SWB coincides with a stage of life characterized by intense work, pressure and eagerness for economic or labor success (Cheng et al., 2017). In midlife, the regret about unmet aspirations in life is also stronger (Schwandt, 2016). These are also the ages at which stress and the consumption of antidepressants increase (Blanchflower \& Oswald, 2016; Fortin et al., 2015).

The U-curve implies that the happiest stages in life are experienced at younger and older ages. Scholars have associated the increase in older people's subjective well-being with a higher satisfaction in terms of material needs and human relations at these ages, the readjustment of expectations in life, the pleasure of anticipating retirement or the fact that happier people tend to live longer (e.g. Plagnol \& Easterlin, 2008; Diener \& Chan, 2011; Steptoe and Deaton, 2015). These aspects would compensate for the expected decline in utility concerning the process of health deterioration, the loss of relatives and friends or the closeness to one's own death (Wunder et al., 2013). Some analyses based on longitudinal data find a more complex course of well-being at older ages. For instance, studies grounded on the longest existing panel data sets from Australia, Germany, and Great Britain ${ }^{1}$ show that, after controlling for usual correlates of SWB and individual fixed effects, happiness slightly varies between 20 and 50 years of age, increases until their late 60 s and finally declines sharply after 75 (e.g. Frijters \& Beatton, 2012; Gwozdz \& Sousa-Poza, 2010; Wunder et al., 2013). Yet other empirical approaches to the same longitudinal datasets do find that SWB scores remain U-shaped in age (Cheng et al., 2017; Clark, 2019).

I try to contribute to this open debate by analyzing the following question: Do individuals identify younger and older ages as the most likely happiest periods in life-in accordance to the U-curve-when they evaluate their lives retrospectively? To answer this question, I exploit information on the age interval at which individuals recall having lived

${ }^{1}$ The German Socio-Economic Panel, British Household Panel Survey and HILDA in Australia. 
their happiest period in life (if any). Data come from the life retrospective survey SHARELIFE - the third wave of the longitudinal Survey of Health and Retirement (SHARE) collected in 2008/09 among a representative sample of citizens (from thirteen European countries) who were born in the first half of the twentieth century and were aged 50 or older at the moment of the interview. In this survey, respondents are asked to report the starting and ending year of their happiest period in life (if any), as well as the dates at which the most salient personal and family events and changes occurred across their lives. Such event history structure makes it possible to build a longitudinal dataset from individuals' date of birth up to the moment of the interview in which we can relate the period each individual identifies as the happiest in life with the age and other personal and social circumstances at that moment. Using this reconstructed life longitudinal panel, I estimate how the probability of achieving the crest of happiness in life (as recalled by respondents) evolves with age, while accounting for changing characteristics and circumstances in life and individual fixed effects.

The analysis offers several novelties with respect to previous literature on the life-cycle of SWB. First, the life history panel obtained from SHARELIFE allows to study the agehappiness relationship throughout the entire lives of the individuals, including the transition from childhood to adulthood, a life stage other surveys usually neglect. Thus, the panel spans throughout a longer period than that covered by existing European longitudinal surveys. ${ }^{2}$ Second, as a measure of SWB, the happiest period in life exhibits some interesting advantages. Individuals engaged in retrospective assessments may adopt different anchor/ reference periods (e.g., present SWB) for the backward evaluation of happiness-thereby complicating comparability between individuals. But, in contrast with the usual measures of current happiness collected in longitudinal surveys, this reference point remains constant; each individual uses the same anchor when assessing their whole life, which eases within-individual comparisons. Another advantage of the happiest period in life is that it requires no use of scales. Moreover, it simplifies memory efforts because it does not require reporting the level of SWB. Indeed it is impossible to make inferences on the level of happiness achieved at each age, but the within-individual approach allows us to infer the most likely age at which the maximum level in life is to be achieved; the latter yields complementary information on life-cycle happiness. Finally, the use of a common methodology across all SHARELIFE participant countries eases the cross-country comparison of results.

The analysis reveals some interesting patterns. The relationship between the probability of living the happiest year in life and age exhibits an inverted-U shape, with a turning point at the age of 30-34 years and a steadily downward trend until the oldest ages. It is interesting that few older Europeans recall childhood as the happiest period in life (even those belonging to cohorts that witnessed no wartime), which coheres with the hardship of the first half of the twentieth century in Europe. In retrospect, the midlife crisis is less evident than in studies based on current happiness assessments of current happiness. On average, this stage of life is judged to be neither the least nor the most likely happiest period in an individual's life. The pattern is similar for men and women, and rather consistent across cohorts and countries. Controlling for individual unobserved heterogeneity and for a large set of changing personal characteristics and life events makes the estimated life-cycle pattern of the probability of highest happiness more uniform, but age differentials define the same profile.

\footnotetext{
2 In Europe, the longest data panels are the German Socio-Economic Panel and the British Household Panel Survey that began in 1984 and 1991, respectively.
} 
This research contributes to the literature advocating the use of alternative measures of SWB. As Stone and Krueger (2018) state, taking a multi-faceted view of SWB matters because the same events and factors may have differential effects on alternative measures of SWB. The use of long-term retrospective information has been uncommon in the analysis of the life-cycle of SWB. The scant psychological literature addressing this question find that adolescence is recalled as a period of low life satisfaction and the most satisfying decade in life is reported to be either in the $30 \mathrm{~s}$ or midlife; this clashes with the U-curve of happiness (e.g. Field, 1997; Lachman et al., 1994; Mehlsen et al., 2003; Gómez et al., 2013; Galambos et al., 2020). This literature offers a fragmented view of how individuals assess their life retrospectively. It is difficult to compare results because the studies apply different sample selection criteria and use heterogeneous question formats (e.g. how satisfied they were with their lives at different ages; identification of the decade that brought them the most satisfaction, etc.). In addition, these analyses do not account for the effect of confounding circumstances and events experienced by individuals throughout their lives. This paper overcomes these limitations thanks to the richness of information on respondents' life course and the common crosscountry methodology of SHARELIFE.

In general, scholars are reluctant to use retrospective well-being reports given the concerns on individuals' recall and cognitive biases (Kahneman \& Riis, 2005; Diener et al., 2001; Wirtz et al, 2003; Fredrikson and Kahneman, 1993). In the same vein, Easterlin (2002) states that retrospective reports of happiness give no information about the utility individuals experienced at that time; instead they tell us how individuals would feel now if they were placed in conditions akin to those of the past. This literature, however, does not undermine the meaning of retrospective information; rather, it suggests that policy implications of analyses based on current SWB and those using retrospective assessments may be different. While the first type of analyses identify well-being enhancing or depressing factors, the way in which individuals revisit and assess their lives in terms of happiness may also identify what builds their preferences and, therefore, what drives decisions. Consequently, empirical results based on retrospective measures should be taken as complementary rather than as substitutes of previous findings based on individuals' assessments of current SWB.

The paper also contributes to the literature on ageing. As mentioned above, literature shows that memory plays an important role in shaping preferences and, therefore, decisions. Hence, analyzing how older individuals remember the past and elaborate on their happiness trajectories across life may help to learn how they perceive ageing. This may be an intermediate step towards understanding their inter-generational resource allocation preferences. The relevance of this issue is evident in societies like Europe where the weight of the "grey vote" is growing (De Mello et al, 2017).

The article proceeds as follows. Section 2 summarizes the main characteristics of SHARELIFE, describes the key variables for the analysis and provides a descriptive analysis on the retrospective measure of happiness. Section 3 presents an econometric approach to study the determinants of the likelihood of achieving a happiest period in life. The main findings of the analysis appear in Sect. 4. Section 5 concludes. 


\section{Data}

\subsection{Sample and Data Structure}

The data for the analysis come from SHARELIFE, a retrospective module included in the third wave of the longitudinal Survey of Health, Ageing and Retirement in Europe (SHARE) in 2008/09 (see Börsch-Supan et al., 2013 for description). The target population consists of individuals aged 50 or older who speak the official language of each country and do not live abroad or in an institution-plus their spouses (or partners), irrespective of age. The retrospective module was collected in 13 countries: Austria, Belgium, Czech Republic, Denmark, France, Germany, Greece, Italy, the Netherlands, Poland, Spain, Sweden, and Switzerland. The sample comprises 26,836 individuals who either participated in the first, the second, or both waves of SHARE.

SHARELIFE provides a historical retrospective review of fundamental events of respondents' lives from their birth to the moment of the interview. The elicitation method used in SHARELIFE is based on a life history calendar approach. This methodology consists in making a computerized "life grid" recording of life events reported by respondents, when they happened, and the starting and ending years in the case of longer episodes. External information on historical events is displayed on a computer screen to help respondents dating their life circumstances (see Schröder, 2011 for methodological details). In their validation studies, Garrouste and Paccagnella (2011) and Havari and Mazzonna (2011) show that collecting SHARELIFE data with this approach greatly reduces the incidence of recall biases in answers.

The original structure of SHARELIFE is cross-sectional. However, it is possible to exploit the timeline of events and life circumstances reported by respondents to reshape the survey into a longitudinal dataset from the birth date of each individual until the year of the interview, so that we have one record per person/year. Brugiavini et al. (2013) and Antonova et al. (2014) use this procedure to build the SHARE Job Episodes Panel Data that reshapes SHARELIFE respondents' information on the employment module and other sociodemographic characteristics, including age. Using the same methodology, I extend this panel with information on individuals' happiest periods in life and with the individual and context variables relevant to the analysis, as described in the next section.

To reduce the potential threat of recall and survivor biases, the sample used in the analysis is restricted to respondents born between 1928 and 1958 (inclusive). Individuals whose questionnaires were answered by a proxy respondent (e.g. relative or caregiver) were also excluded. In order to ease the identification of some context factors, I focus on those born in the same country where they are residing at the time of the interview. Individuals who lived abroad for some period(s) in life are also included. Therefore, inferences are conditional to the 20,658 individuals who meet these restrictions. After having dropped all observations lacking valid information concerning the variables used throughout the analysis, our final sample consists of 17,322 individuals aged between 50 and 80 whose lives were fully reconstructed from their date of birth to the year of the interview. ${ }^{3}$ Finally, since

\footnotetext{
3 In further analyses (not displayed in the paper but available upon request), I find that the individuals included in the sample do not systematically differ-in terms of the life-cycle pattern of the happiest period in life-from those who were excluded due to missing information in control variables. This suggests that the drop of individuals with missing information does not condition the findings of the paper to an important extent.
} 
recall periods for several questions in SHARELIFE start at the age of 10, I restrict the empirical analysis to the history of individuals from the age of 10 to their respective present ages. The total number of observations in the dataset is 954,044 .

\subsection{The Happiest Period and Other key Variables}

The key information for the analysis is individuals' identification of their happiest period in life collected through the following SHARELIFE questions:

Looking back on your life, was there a distinct period during which you were happier than during the rest of your life? (If yes,...) When did this period of happiness start? When did this period stop?

When the respondent answers these questions, the computer screen displays a timetable with a set of relevant personal events that had happened to individuals along the course of their lives. This procedure facilitates the emotional recall of what they were living at those moments; so it yields a more accurate assessment of the corresponding level of well-being or happiness. We cannot discard that the events described on the screen exert a priming effect on responses, which can even be exacerbated by cultural biases. That is to say, individuals may tend to simplify their memory effort by identifying as their happiest period one including the events displayed on the screen usually (or culturally) considered as happy moments in life (having a child, marriage, the first job, etc.). Unfortunately, we cannot identify the relevance of this potential source of bias with the data on hand.

Appendix Table 1 summarizes some descriptive statistics of individuals' answers on the happiest period in their life. Fewer than half of the respondents report to have lived a salient period of happiness. This percentage varies sizably across countries and gender, with women being more likely to report a happiest period in life (48\%) than men (39\%). The oldest respondents in our sample-born between 1928 and 1938 - are less likely (than are individuals from younger cohorts) to recall a distinct period of happiness. This preliminary evidence challenges the hypothesis of a generalized changing life-cycle pattern of (remembered) happiness. In this sense, Frey and Stutzer (2002) observe that higher levels of wellbeing are often transitory across the lifespan; this may explain why so many individuals do not recall any salient happiest period. The median duration of the spell of highest happiness is around 21 years for both male and female respondents; the length of this interval decreases as we move from older to younger cohorts. It is important to remark that we cannot make any inference on whether the life average level of happiness of those who do report a happiest period is higher or lower than the one corresponding to those who do not identify such a period in life. What we can state is that the first group of respondents experienced higher variation in happiness across life-so they can identify a significant happiest period - than the second one. In the life panel, I codify this information on the happiest period in life as a binary variable that, for each individual, takes the value 1 for all the corresponding years from the start to the end of the recalled episode (and 0 otherwise).

Using the SHARE Job Episodes Panel Data, I identify whether each respondent was working, unemployed, or inactive in each year of life. Inactive status is further split into three categories: study, retirement and other type of inactivity. In addition, I build a new variable that recovers the stock of schooling years achieved at each moment in life.

Respondents report married and unmarried partners across life, when these relationships started, and when (and why) they ended. In order to simplify this information and reduce inconsistencies in classifying years according to legal civil status and cohabitation status 
as much as possible, I use the dummy variable provided by the Job Episodes Panel that distinguishes between two types of life periods: cohabiting with a married or an unmarried partner; or not cohabiting. The total number of children born (or adopted) up to each year is included through dummy variables indicating the number of sons and daughters each year: zero, one, two, three or more. Also, I generate four dummies that indicate the year of occurrence of the following family events: formation of own household, death of a (married or unmarried) partner, childbirth, and death of a child.

The oldest cohorts interviewed in SHARELIFE grew up during the first half of the twentieth century - a turbulent and violent period in Europe. I exploit information on the country of residence at each year of life to construct an indicator for individual war exposure. This variable takes value 1 for respondents living in Austria, Belgium, Czech Republic, France, Germany, Greece, Italy, Netherlands and Poland during World War II (1939-45) and those living in Spain and Greece during 1936-49 and 1946-49, the periods corresponding to their respective civil war periods. For all other periods and countries of residence, the war dummy takes the value 0. Furthermore, SHARELIFE includes explicit questions on whether, when and for how long, respondents faced a salient episode of hunger, financial hardship, stress, illness or dispossession due to persecution. I codify the answers to each question as dummy variables that takes the value one at each year if the respondent was living such an episode and zero, otherwise. From the history of living accommodations I build another dummy variable to account for periods in which the respondent lived in institutions such as orphanages, mental hospitals, nursing homes for the elderly, prisons or labor/concentration camps. Appendix Table 2 displays the prevalence of different sociodemographic characteristics and life events across individuals' life course.

Finally, I exploit information on the individuals' country of residence at each age to impute the GDP per capita at constant PPP dollar by using the Maddison Database (Maddison, 2010; Bolt et al., 2018).

\subsection{Descriptive Analysis}

As a first approach to the life-cycle pattern of individuals' happiest period, Fig. 1 displays (by birth cohort and gender) the share of respondents who, at each age, identify that year as one of the happiest in life. Although the empirical analysis is confined to ages 10 or higher, these graphs also include data for earlier childhood for descriptive purposes.

In Panel A of this figure, I compare three birth cohorts of individuals defined as follows: born between 1928 and 1938, born between 1939 and 1948, and born in 1949 or later. We observe three remarkable features. First, the percentage of individuals identifying childhood as the happiest period is very small for all three cohorts, showing very slight differences among them. Second, the share of individuals living their happiest period steadily increases from childhood to its peak in their 30 s and then decreases, exhibiting an inverted U-shaped relationship. Third, the oldest respondents in our sample-born between 1928 and 1938-are more likely (than are individuals from younger cohorts) to recall some period after their 30s, as the happiest in their lives. In Panel B, we can see that the shares of men and women who identify childhood as the happiest period in life are similar and below 5\%. About 30\% (23\%) of women (men) recall having lived their happiest period in life when they were in their 30s. This gap may reflect the differential effect that family formation events (e.g. childbirth) have on women's happiness relative to men's, as we will see later. The gender gap shrinks at older ages - primarily due to the dramatic reduction in the share of women living their happiest years-and even reverses from age 65 onward. The 
percentage of respondents between the age of 70 and 80 who have lived (or are living) their happiest period in life falls on the interval $15-18 \%$.

Figure 2 displays cross-country patterns. Seeking to maximize the number of observations of country subsamples, I pool together male and female respondents. Scales have intentionally not been unified in order to ease the visualization of age patterns.

Overall, the proportion of individuals in their happiest years displays an inverted-U shape in all countries, though some cross-country differences are present in the magnitude of shares and their evolution at older ages. French respondents are the most likely to report having lived a happiest period in life at any age; the percentages for this country achieve $15 \%$ in childhood, $50 \%$ at midlife and no less than $40 \%$ at older ages. By contrast, the shares are relatively low (below 20\%) at all ages in Germany, the Netherlands, Denmark and Switzerland. This finding suggests that respondents from these countries recall, on average, more uniform lives in terms of happiness than those from the rest of countries included in the sample. Another diverging pattern appears in the evolution of the share of individuals in their happiest year in life with age. In some countries, like Austria, France and Sweden, the share remains quite uniform from the age of 30 onward whereas we observe a downward trend along that age interval for the rest of countries.

Do individuals' reports on the happiest period in life cohere with other indicators of subjective well-being? Fig. 3 compares the share of men and women in our sample-by their age at the moment of the interview-who include the year of the interview within the happiest period of their lives, jointly with the average level of current life satisfaction (Panel A) and the average level of a depression score (Panel B). These two latter indicators are elicited through the main questionnaire of SHARE. Current life satisfaction is elicited through the drop-off questionnaire of $\mathrm{SHARE}^{4}$ and it is measured on a $0-10$ scale; the EURO-D scale is a validated index that measures depression levels. This is a generated variable from questions of the SHARE health module. A EURO-D score greater than 3 indicates a clinically significant depression (Prince et al., 1999). The age patterns of these three measures of subjective well-being are highly consistent with each other. The cross-sectional comparison shows that women exhibit a lower level of SWB in these three dimensions. In addition, older respondents tend to report worse levels of life satisfaction and depression, and they are less likely to identify the year of the interview as one of the happiest in their lives than are individuals in their 50s.

In the next section, the validity of individuals' reports will also be judged from the coherence of the timing of the happiest period in life and the timing of usual predictors of subjective well-being.

\section{Empirical Approach}

This section presents the econometric model for estimating the relationship between age and the probability of achieving maximal happiness in life. Let us denote $h_{i c t}$ the binary variable that, for each respondent and each year, is set to 1 if the year belongs to the happiest period in the individual's life (and to 0 , otherwise). The probability of reporting year $t$ as one of the happiest in life is specified as a fixed effects logit model:

\footnotetext{
${ }^{4}$ This is a self-completed paper-and-pencil questionnaire that SHARE participants complete just once. We use answers to the drop-off questionnaire in wave 1-except for the Czech Republic and Poland, where we collected this information in wave 2 .
} 
Panel A: Cohorts

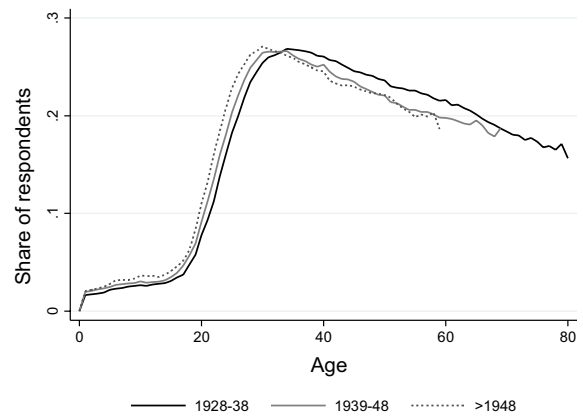

Panel B: Gender

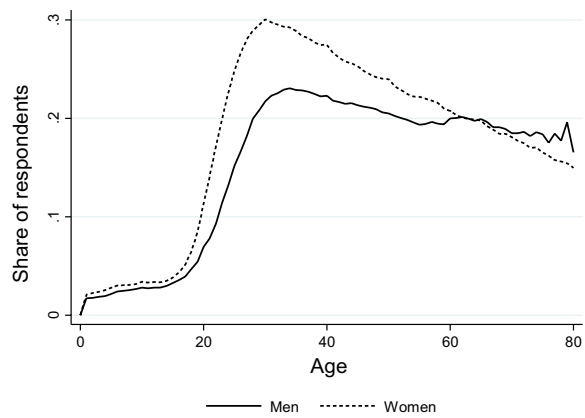

Fig. 1 Share of respondents that identify having lived the happiest year of life at each age, by birth cohort and gender. (The graphs display the share of respondents in our sample who report having lived the happiest period in life at each age. The corresponding sample sizes are displayed in Appendix Table 1)

$$
\operatorname{Pr}\left(h_{i c t}=1 \mid a_{i t}, x_{i t}, z_{c t}, v_{i}\right)=\frac{\exp \left(a_{i t}^{\prime} \beta+x_{i t}^{\prime} \gamma+z_{c t}^{\prime} \delta+\mu_{t}+v_{i}\right)}{1+\exp \left(a_{i t}^{\prime} \beta+x_{i t}^{\prime} \gamma+z_{c t}^{\prime} \delta+\mu_{t}+v_{i}\right)},
$$

where vector $a_{i t}$ includes a set of dummy variables for five-year age intervals (the reference age category is 10-14 years). The variable $v_{i}$ denotes individual fixed effects controlling for intrinsic differences in happiness that may be driven by personal traits (e.g., intelligence, neuroticism, optimism) and could affect happiness levels as well as the likely occurrence of certain personal events. ${ }^{5}$ It may also capture the effect of unobserved explanatory variables remaining constant over time, such as country and birth cohort. Controlling for individual fixed effects implies that the age effects are identified only from within-individual variations. In other words, the estimates allow identifying how the probability of achieving maximum happiness changes at each age interval (relative to the probability at the reference age of 10-14 years), once unobserved individual heterogeneity remains constant. The model also includes time effects through 5 -year dummies. ${ }^{6}$

The inclusion of additional controls is a controversial issue in the empirical literature on the life-cycle pattern of SWB. Advocates of this strategy consider this is important in isolating the "pure age effect" from the effect of other changing characteristics and circumstances (e.g. Blanchflower \& Oswald, 2008, 2019), whereas critics argue that most of these controls may in fact be bad controls that mediate the effect of age and thereby render misleading conclusions on the life-cycle pattern of SWB (e.g. Cheng et al., 2017; Easterlin, 2006; Glenn, 2009). Here, the empirical strategy consists in including them sequentially, so we can explore the extent to which they affect the estimated life-cycle pattern. Accordingly, in model (1), $x_{i t}$ denotes individual characteristics and personal events that vary across life;

\footnotetext{
${ }^{5}$ Using and linear regression model, Frijters and Beatton (2012) show that, even if age is not correlated with omitted fixed effects, the coefficients on age could be biased if the model includes time-varying controls that change systematically with age and are correlated with the omitted fixed-effect.

6 To check if results are sensitive to the definition of time dummies, I have re-estimated the specification with the full set of controls by including year fixed effects: the results remain robust and do not substantially differ from those obtained using 5-year dummies.
} 

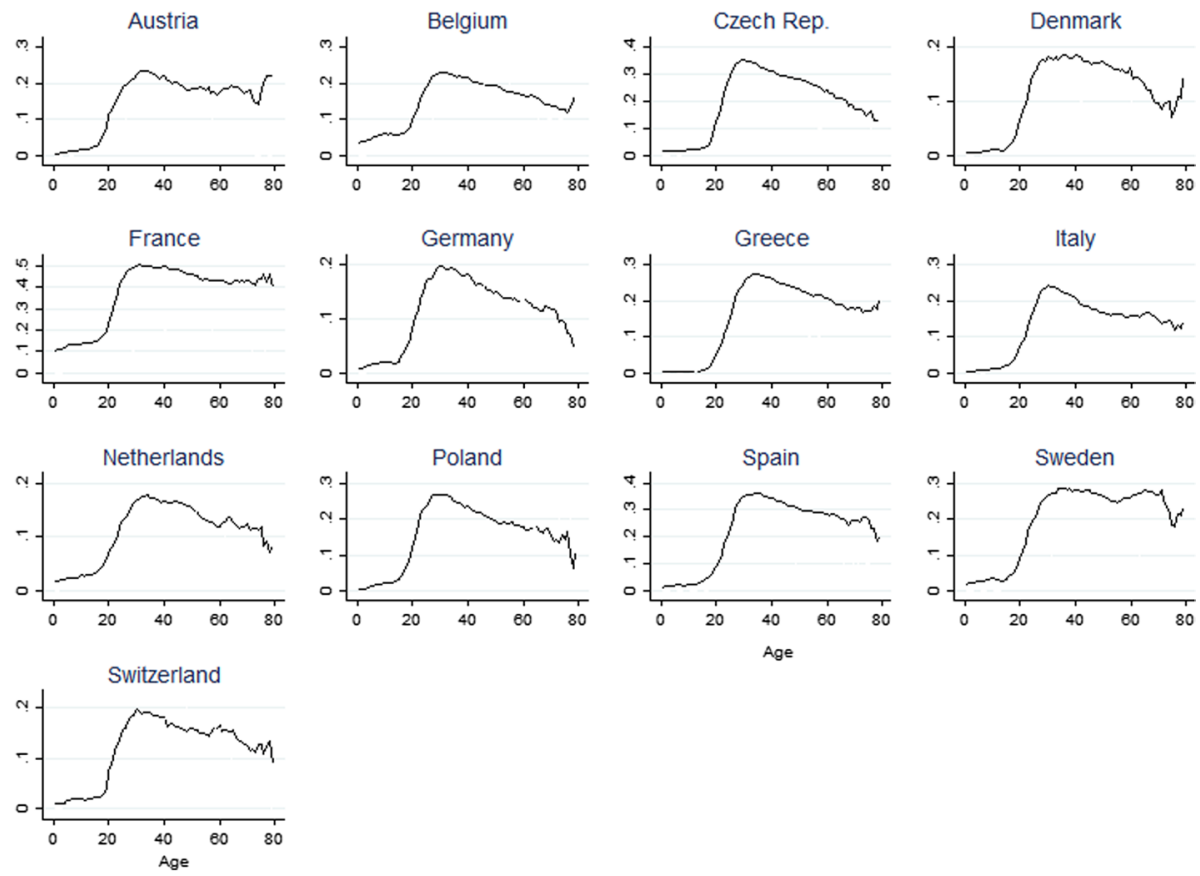

Fig. 2 Share of respondents identifying salient periods of happiness at each age, by country. (In these graphs, men and women are pooled together. The corresponding sample sizes are displayed in Appendix Table 1)

Panel A

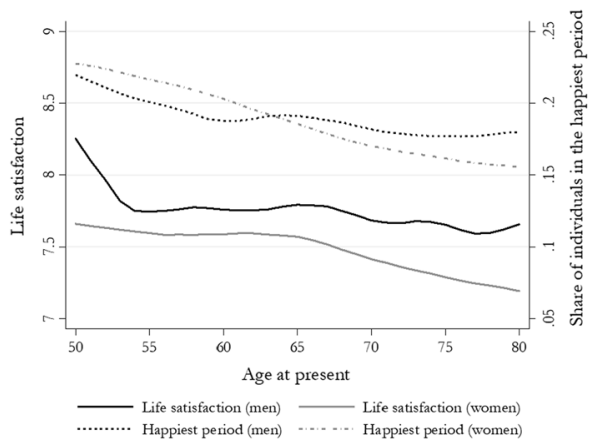

Panel B

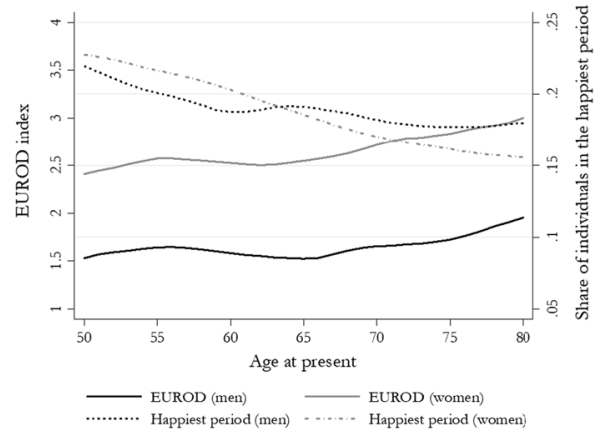

Fig. 3 Happiest period, life satisfaction and depression at the moment of the interview. (Graphs plot kernel-weighted local polynomial smoothing of each variable as a function of age. Current life satisfaction is measured on a scale 0-10; a European Depression (EURO-D) score greater than 3 indicates clinically significant depression; the happiest period is measured through a binary variable indicating whether the respondent is living his/her happiest period in life at present or not. The sample used in this graph is further restricted to respondents providing valid information on life satisfaction and EURO-D in the main core questionnaire of SHARE) 
and the vector $z_{c t}$ includes a set of country-level variables for events in and features of the individual's country of residence during year $t$ - such as war periods and per capita GDP, at constant prices.

Chamberlain (1984) demonstrates that model (1) can be estimated via the conditional maximum likelihood method, which eliminates the problem of incidental parameters bias. Yet this approach imposes a strong restriction on data: only those who report a distinct period of happiness contribute to the likelihood function. This raises the question of whether or not individuals who report a salient happy period in life and those who do not report it are similar in observed and unobserved characteristics that may also affect the conditional probability of classifying a year as the happiest in life. This would cause a selection bias problem. One particular concern is that individuals with certain unobserved personality traits (e.g., optimism) were more likely to report a salient period of happiness than individuals lacking that trait. Insofar as any trait increases the likelihood of classifying as the happiest year one in which certain events occur-conditioned on having identified a distinct period of happiness - we would overestimate the effect of such events in comparison with their effect on the overall sample.

In Appendix B, I use the cross-sectional structure of SHARELIFE to analyze the correlates of the probability of reporting a distinct period of happiness in life. The specification includes individuals' characteristics, whether they were affected by different types of events across the life course, as well as proxies for personality traits such as optimism, and current level of life satisfaction. It is interesting that, though the probability of identifying a happiest year in life is significantly correlated with the respondents' current life satisfaction or their level of optimism, ${ }^{7}$ these personality traits are no longer significant once we control for the rest of explanatory variables. The findings suggest that what leads individuals to identifying a distinct period of happiness is what happens to them across life (life events, changing family circumstances, etc.) rather than their personality traits. Such evidence reduces-but does not eliminate-the concern that results are severely affected by selection bias, since the empirical model includes controls for these time-varying characteristics and events.

There are other potential sources of bias. Over the life cycle, selection favors happier individuals because unhealthier people are both less happy and more likely to die. Havari and Peracchi (2017) note that, in SHARELIFE, such selection is minimal until age 70, when three fourths of the cohort alive at age 18 are still living. By age 80, however, the proportion of survivors has been halved. This restriction is likely to generate an upward bias in analyses based on reported levels of current SWB. However, it is unclear whether (and in which direction) this bias appears when individuals retrospectively identify the happiest period in their lives.

Finally, we cannot disregard the possibility of measurement errors due to mistakes in reported dates or inconsistencies in answers and recall biases. Analyzing the likelihood of such biases would require comparing respondents' SHARELIFE answers with register data or some other information-based survey, which is unfeasible.

\footnotetext{
7 The coefficient estimates (and robust standard errors) of the probability of reporting a salient period of happiness on the variables "Always find ways to solve problems", "Always optimistic about future" and "Current life satisfaction"-obtained through three separate probit specifications_are $0.027(0.016), 0.090$ (0.030) and $-0.038(0.019)$, respectively.
} 


\section{Results}

\subsection{How Does the Likelihood of Achieving Maximal Happiness Evolve with age?}

This section presents the conditional fixed effects logit estimates for various specifications of model (1) that differ in the set of added controls. Appendix Table 3 displays the results separately for men and women.

Figure 4 reproduces the estimated coefficients for age dummies in all these specifications for men (Panel A) and women (Panel B); the youngest age group (10-14 years) is the reference category. The uppermost line (black circles) in Fig. 4 corresponds to the estimated coefficients from a specification without additional controls. The inverted-U pattern reproduces the descriptive findings presented in Panel B of Fig. 1. On average, the estimates indicate that the likelihood of achieving the happiest period in life increases substantially between childhood and the ages of 30-34, where it achieves the maximum. From then onward, the probability decreases, though it does so more sharply for women than for men.

Including controls for individuals' sociodemographic characteristics (i.e. cohabitation status, number of children, labor status and education attainment) at each year of life leads to sizable declines in the estimated age differentials between childhood and young adulthood (lines with gray squares). These controls reduce age differences in women's probability of achieving maximal happiness to a greater extent than they do for men. This finding suggests that large increases in the probability of living the happiest period at those stages of life are mainly attributable to changes in personal circumstances tending to occur at those ages - and not only to a pure aging process. For instance, estimates in Appendix Table 3 reveal that periods of cohabitation with a partner and periods with children are significantly associated with a higher probability of living the happiest period in life than periods of no cohabitation and periods with no children, respectively. The most important transitions in these family-related characteristics happen between adolescence and the age of 30 (see Appendix Table 2). Therefore, controlling for them smooths the estimated changes that were previously associated with the transition from childhood to young adulthood. Note that this set of controls includes personal circumstances and events displayed on the computer screen at the moment of the interview. Therefore, as previously suggested, we cannot discard that part of the variation in the probability of living a happiest period in life that is attributed to those experiences reflects some priming effect.

In a third set of lines (gray triangles), the model includes additional controls for individuals' experience of several personal and context-driven life events. With the exception of forming one's own household and the birth of children, which have positive effects on happiness, the other life events for which we control (hunger, stress, illness, institutionalization, death of a child or a partner) are negatively associated with the likelihood of identifying that year as being an exceptionally happy one (see Appendix Table 3). Including these variables reduces the gap in the probability of highest happiness between an age of 30-34 and older. Finally, the fourth specification (hollow circles) incorporates indicators for contextual variables, i.e. a dummy that identifies war versus peace periods and per capita GDP at constant prices (logged). The inclusion of these controls makes no significant difference in the estimates.

One limitation of using conditional fixed effects logit estimation here is that the only individuals contributing to the likelihood function are those reporting a distinct period of happiness. Figure 10 in Appendix A compares the conditional logit fixed effects estimates 
on the effect of age with those obtained from random effects logit specification to explore whether, or not, our results are being driven by the estimation method. The random effects specification is more restrictive-because it assumes that unobserved individual effects are uncorrelated with the explanatory variables - than are that of the fixed effects type; however, it has the advantage of not requiring the exclusion of observations from the estimation. Regardless of the specification adopted, no relevant discrepancies are present between the estimated patterns.

The coefficient estimates displayed in Fig. 4 give no information about the intensity of effects; estimating average marginal effects would require setting arbitrary values for individual fixed effects. Then, following Kemp and Santos-Silva (2016), I quantify the magnitude of changes by computing average age semi-elasticities (and the corresponding $95 \%$ confidence intervals) with the specifications that include the full set of controls. These estimates are obtained using all individuals in the sample, not only those who contribute to the likelihood function. Results are displayed in columns [5] of Appendix Table 3. The average semi-elasticities for each age group are reproduced in Fig. 5.

Each point in the graph (multiplied by 100) is the estimated average percentage change in the probability of living a happiest period in life at each age interval relative to the ceteris paribus probability at the age of 10-14. Overall, we observe no significant differences in how the probability of living the happiest period in life evolves with age for men and women. The absence of gender differences in the age patterns of SWB has been found in other studies (e.g. Stone et al., 2010). The estimates indicate that, by the age of 30-34, the probability of a man (woman) reaching his (her) happiest period in life is, on average, roughly $97 \%$ (109\%) higher than at the age of 10-14, ceteris paribus. The largest increase within this age interval happens in the transition between adolescence (15-19) and the age of 20-24. This result contrasts with other findings from longitudinal studies based on individuals' reports of current levels of life satisfaction that show a drop in well-being between the ages of 16-19 and 20-24 (e.g. Clark, 2019).

From the ages of 30-34 onward, the estimates in Fig. 5 display a downward trend in the likelihood of living the happiest period in life that becomes slightly steeper for women than it does for men. Consistent with most related literature, midlife appears to be a stage of life in which SWB decreases. For instance, if we compare the average semi-elasticities at the ages of 30-34 and at midlife (50-54), we infer that the probability of achieving the crest of happiness in life declines, on average, roughly $18 \%$ for men and $23 \%$ for women between these two age intervals, ceteris paribus. ${ }^{8}$ Yet the estimates in Fig. 5 suggest that, in retrospect, this stage of life is not the least likely happiest, on average. A similar result appears in other studies analyzing individuals' identification of the best (or most satisfying) decade in their lives (Galambos et al., 2020). It is interesting that men at the age of 60-64-before the usual retirement age-experience a slight recovery in the chance of achieving maximum happiness in life. This result is consistent with other research findings that document an increase in the level of happiness related with the anticipation of retirement (e.g. Frijters \& Beatton, 2012). However, in the present analysis, this upward variation entails no

\footnotetext{
${ }^{8}$ For men, this variation rate is obtained as follows. Let $P_{0}$ denote the average probability that a man reaches the crest of happiness at the reference age category (10-14 years). The estimated average semielasticities (see column [5] in Appendix Table 3) imply that, by the age of 30-34, the ceteris paribus probability will be, on average, $96.6 \%$ higher than at the reference age category, so this probability would be equal to $1.966 \times P_{0}$. Likewise, the ceteris paribus probability level at the age of 50-54 would be $1.606 \times P_{0}$. Thus, the variation rate in the probability of living the happiest period in life between these two age intervals would be roughly $-18 \%$. The computation is similar for women.
} 


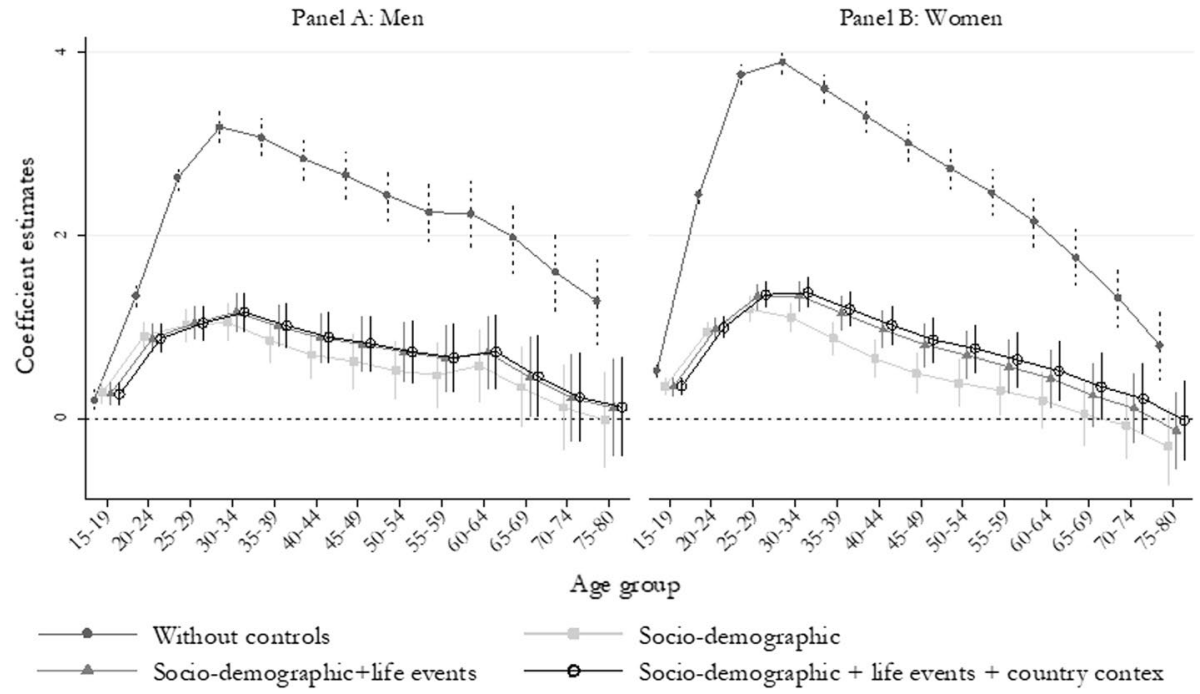

Fig. 4 Age coefficient estimates on the probability of living a happiest year in life. (The graphs reproduce conditional fixed effects logit estimates of the probability of identifying a year as the happiest in life (see Appendix Table 3). Plotted values are conditional logit coefficient estimates and 95\% confidence intervals for the dummies of age groups (reference age group: age 10-14 years). All specifications control for individual and time fixed effects through 5-year dummies)

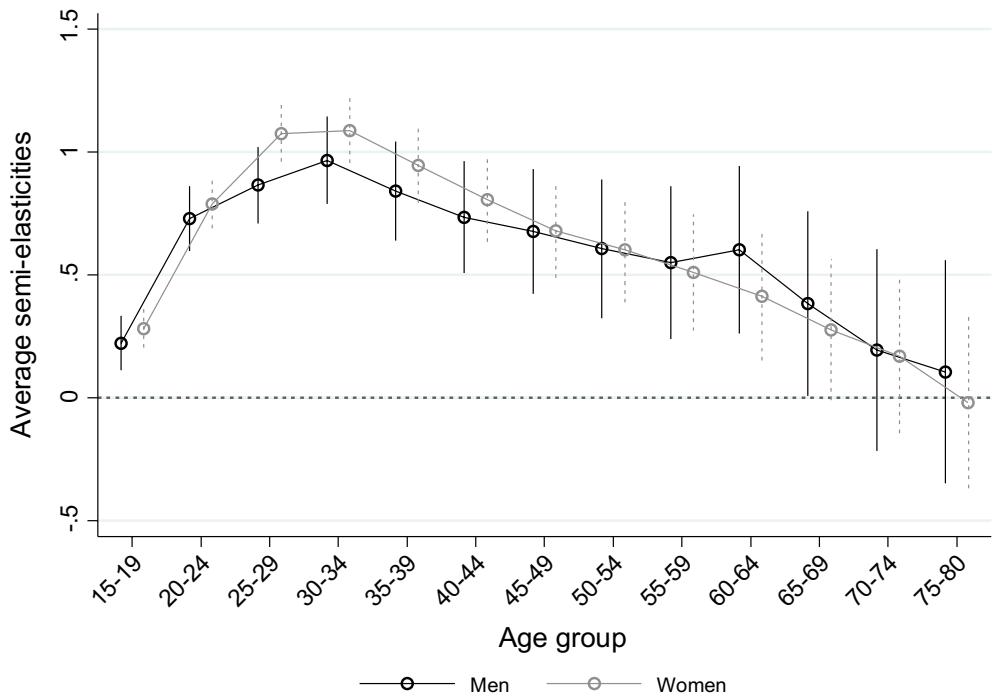

Fig. 5 Average age semi-elasticities of the probability of living a happiest year of life, by gender. (The figure reproduces conditional fixed effects logit estimates displayed in columns [5] of Appendix Table 3. Plotted values are the estimated age semi-elasticities (relative to the ages 10-14), along with their corresponding $95 \%$ confidence intervals, obtained for men (black circles) and women (gray circles)) 


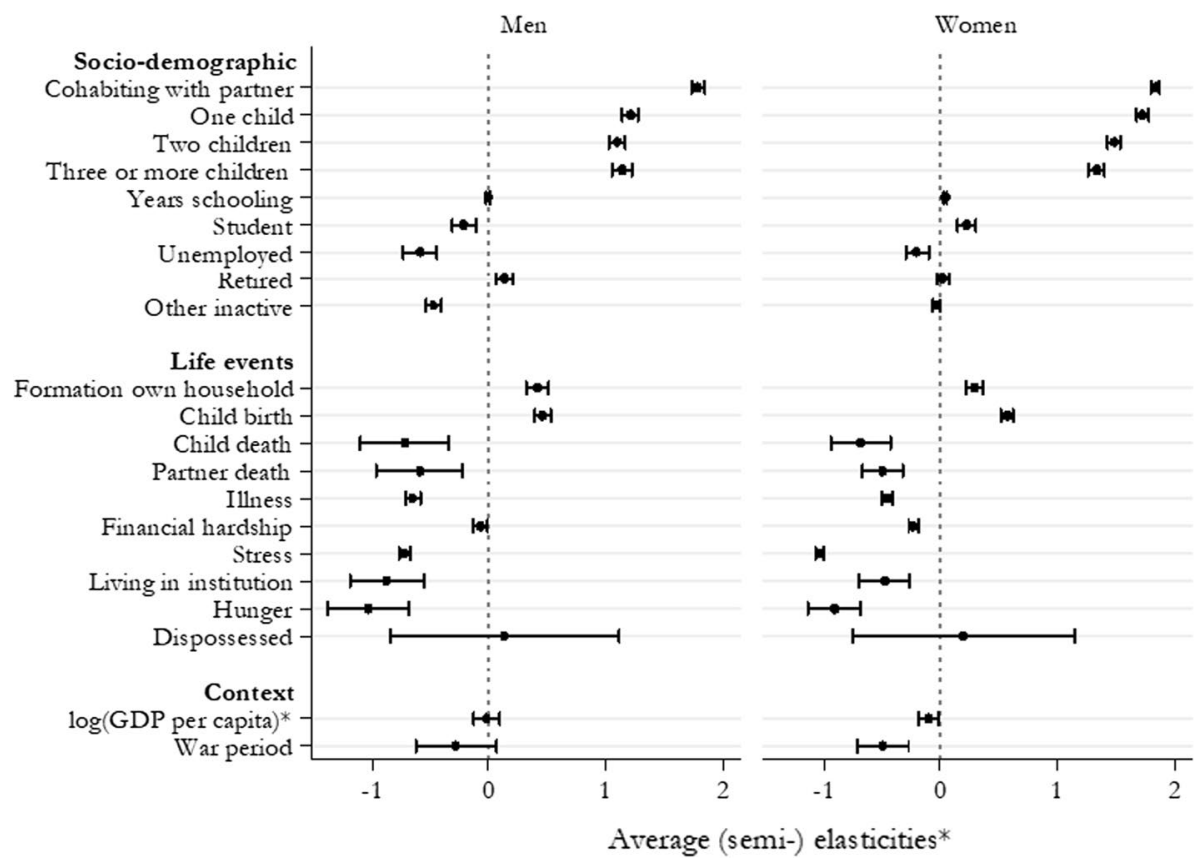

Fig. 6 Estimated average (semi-)elasticities on other covariates of the probability of living a happiest year of life. (Plotted values are conditional fixed effects logit estimates. The graphs reproduce results in columns [5] of Appendix Table 3. They display the estimated average age semi-elasticities (and 95\% confidence intervals), for dummy variables, and the average elasticity for log (GDP per capita) of the probability of living a salient period of happiness)

statistically significant difference with respect to the decreasing trend observed for women at those ages.

Finally, the estimates reveal that the probability of living the happiest period in life declines even further at older ages. From age 70-74 onward, the probability becomes statistically equal to the probability at the age of 10-14. Note that the estimated age differentials are highly imprecise at those ages, due to the small sample sizes; inferences should therefore be drawn cautiously. Even so, they are not compatible with any recovery in the happiness trajectory.

\subsection{Does the Timing of the Happiest Period in Life Cohere with the Timing of Known Correlates of SWB?}

Figure 6 reproduces the estimated effects of the rest of explanatory variables. With the exception of the logarithm of per capita GDP, for which the estimate is the average elasticity, the graph displays average semi-elasticities corresponding to each included control (see column [5] in Appendix Table 3). Overall, results indicate that respondents associate the happiest periods in their life with events and circumstances that the literature identifies as correlates of standard SWB measures. Such coherence can be interpreted as a validation check for the happiest period in life as a measure of some dimension of individual well-being. 
Periods of cohabitation with a partner are significantly more likely to be associated with salient happy periods than are those of non-cohabitation. Likewise, parenthood significantly increases the probability of achieving a maximum happiness in life with respect to periods without children. The years of child birth are about $46 \%$ more likely to be included in the happiest period in life than other years. Besides the event itself, the presence of children in the family significantly increases the probability of maximal happiness with respect to periods without them. For women, the largest positive change is associated with the first child (170\%); for men the incremental change is about $50 \mathrm{pp}$. smaller than for women and remains almost the same when the number of children increases.

As regards labor status, the estimates reveal that the average probability of a male (female) respondent identifies an unemployment period as the happiest in life is $59 \%$ (20\%) lower than the ceteris paribus probability for a working period. For men, the effect is much larger than the one associated with a salient period of financial hardship, which reinforces previous evidence that unemployment episodes entail costs beyond the loss of income and consumption (Winkelmann and Winkelmann, 1998). In contrast, retirement increases, ceteris paribus, the probability of maximum happiness by $14 \%$ for men but is not significant for women. For women, education periods are more likely to be identified as the happiest in life than working periods; for men, we find the opposite result. It is also interesting that women's probability of high happiness increases with the stock of years of schooling achieved across life, whereas this variable is not significant for men.

The average semi-elasticities corresponding to positive and negative life events have the expected signs and are statistically significant and large in magnitude, with the exception of those corresponding to having been dispossessed due to persecution which are estimated with very low precision. The drops in the probability of living a happiest period in life associated with periods of hunger, stress, illness and institutionalization episodes are sizable; the estimated changes due to these events are statistically similar to the effects of the death of a partner or a child. As expected, war periods are less likely to be identified as the happiest in life than are peace periods, though the difference is not statistically significant for men. Surely, part of the effect of this indicator is already captured by the experience of other circumstances (e.g. hunger, stress, institutionalization, etc.) that are outcomes of wartime. Finally, the level of $(\log )$ per capita GDP is statistically insignificant for men but has a negative and statistically significant effect on women, though the effect is quantitatively negligible.

\subsection{Heterogeneity of the Life-cycle Pattern Across Cohorts and Countries}

European citizens from different countries and/or belonging to different cohorts have been exposed to different opportunities, social norms, welfare state coverage and other circumstances that may affect the life-cycle pattern of recalled happiness. To investigate these potential sources of heterogeneity in age patterns, I have re-estimated model (1), with the full set of controls, in subsamples by country and cohorts. Men and women are pooled together to maximize the sample sizes.

Figure 7 reproduces the estimated age semi-elasticities of the probability of living the happiest period in life (and their 95\% confidence intervals), by cohorts defined as in Fig. 1 (Appendix Table 4 displays the full set of estimates). We observe that, once we control for individuals' experience of the same type of circumstances at each moment in time, the likelihood of living the happiest period in life increases from childhood to young adulthood 


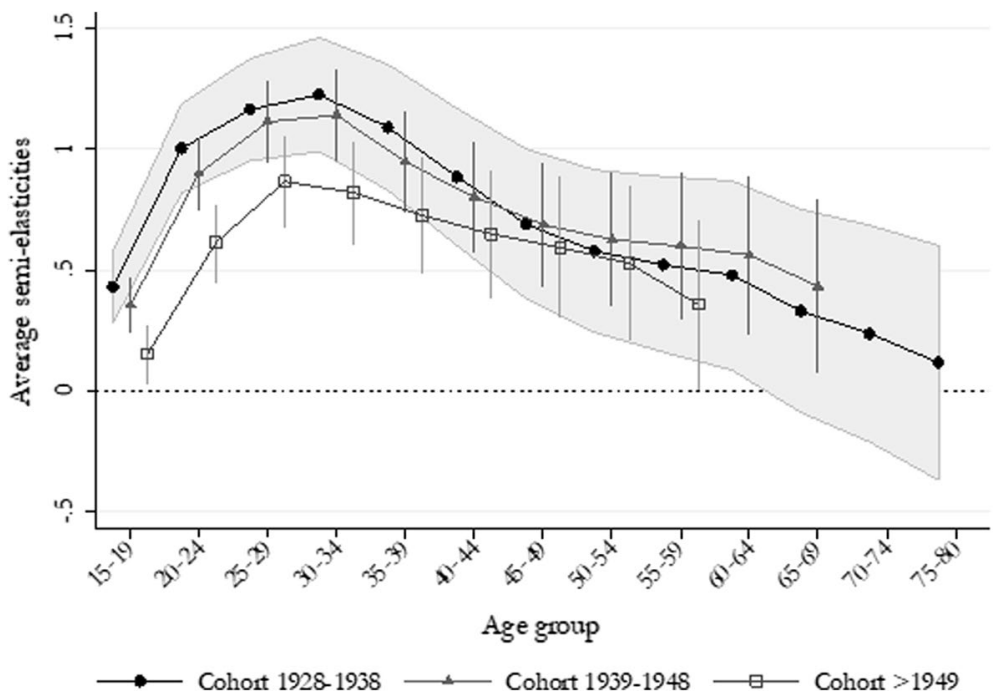

Fig. 7 Average age semi-elasticities of the probability of living a happiest year of life, by cohort. (Plotted valued are estimated average age semi-elasticities (and 95\% confidence intervals); the reference age group is 10-14 years. The grey area depicts the confidence interval for estimates corresponding to the birth-cohort 1928-1938. Models include the full set of controls and are estimated by pooling together men and women)

in the three cohorts, but the slope is steeper for the two oldest cohorts than it is for "baby boomers" (i.e. respondents born after 1949). After the peak, the decline in the probability is less pronounced for this cohort than for the oldest ones, which implicitly defines a rather uniform probability of living the happiest period in life along subsequent years up to the age of 50-54.

Without further analyses, any attempt to identify the source of cohort heterogeneity is speculative. As mentioned above, different generations faced different experiences throughout different historical periods. In this sense, the higher variability in the age pattern of happiness of the oldest generations may well reflect the profound economic, social and political upheavals that marked the first half of the twentieth century in Europe. Respondents born between 1928 and 1938 grew up during war and postwar years; between childhood and young adulthood, they witnessed the start of peace and economic recovery in Europe. This would be consistent with the large increase in the probability of living a salient period of happiness at their 20s and 30s. Heterogeneity of patterns may also arise because respondents belonging to different cohorts assess their past from different current levels of subjective well-being. In Fig. 2, we saw that the oldest SHARELIFE respondents judge the past from lower levels of current SWB than do individuals in their 50s. The extent to which individuals consider their present situation as anchor points for retrospective evaluation might condition the way they judge the past. In this sense, cohort differences in Fig. 7 would suggest that the worse the current level of SWB is, the better the past looks relative to the present.

Figure 8 summarizes the main findings on cross-country heterogeneity. In line with other evidence in literature based on more standard SWB measures, we observe that life-cycle patterns are not universal, but they do share some common features (e.g., Blanchflower, 2020; Deaton, 2008; Graham \& Pozuelo, 2017; Van Landeghem, 2012). In this case, we observe that the dominant pattern is a concave profile that peaks either 


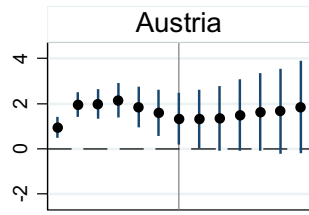

France

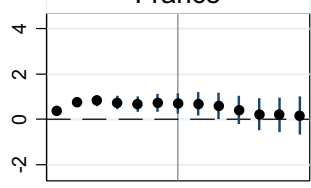

Netherlands
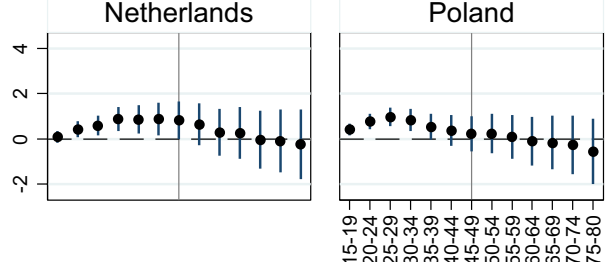

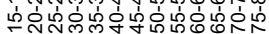

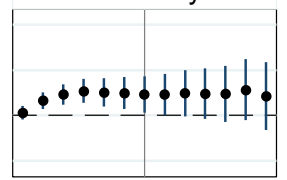

Poland

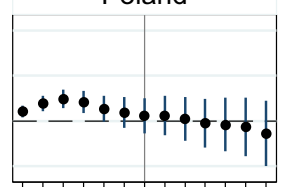

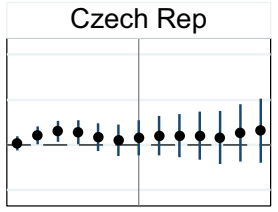

Greece

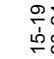
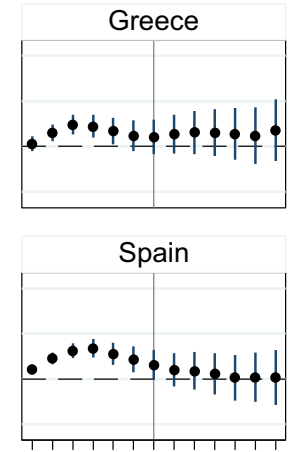

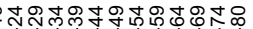

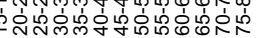

Age group

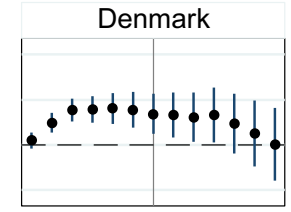

Italy

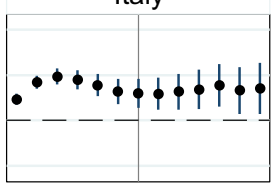

Sweden

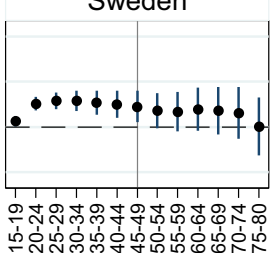

Switzerland

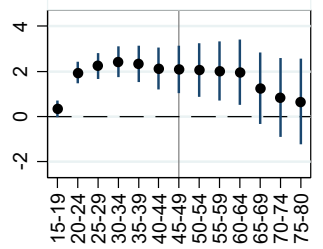

Fig. 8 Average age semi-elasticities of the probability of living a happiest year of life, by country. (Plotted values are conditional fixed effects logit estimates. The graphs display the estimated average age semielasticities (and 95\% confidence intervals) of the probability of achieving a distinct period of highest happiness in life; the reference age group is 10-14. Country subsamples include men and women. Dummies for time fixed effects have been replaced by a time trend and its square. The set of added controls corresponds to specification [4] of Table A3. The war indicator was excluded from models for Denmark, Sweden, and Switzerland)

at the age of 25-29 or 30-34, depending on the country. At these ages, the differential in the probability of living a salient happy period with respect to the chance of living it in childhood is sizable in countries like Austria, Denmark, Switzerland, Sweden, Italy and Spain. Cross-country variability increases when we look at the estimates corresponding to older ages. Thus, the probability of achieving maximal happiness remains rather uniform until midlife in North and Central European countries, whereas it declines steadily in the Eastern and Mediterranean countries included in the sample.

Explaining country heterogeneity is complex. The strength of welfare states and their capacity to prevent subjective well-being downturns caused by financial and health risks across life could be a potential factor. As a mere exploratory analysis of this hypothesis, Fig. 9 relates the threshold age at which the probability of living a happiest period in life becomes statistically similar to the probability in childhood-where the minimum seems to be achieved-and current expenditure in social protection per inhabitant in 2008, expressed in common currency (PPS). 
The graph shows a positive correlation between these two variables indicating that, in countries with higher social expenditure individuals take longer to enter into the stage of life in which probability of achieving maximal happiness in life is minimal.

Obviously, from this information, it is not possible to derive any causal relationship between the life-cycle pattern of happiness and the strength of welfare state because the graph only considers the social protection at the moment of the interview, not across individuals' life span. Nonetheless, the fact that the probability of living the happiest period in life vanishes at older stages of life in countries with a higher the level of per capita expenditure on social care than it does in countries with lower levels of expenditure is consistent with other findings showing that more generous welfare state policies are associated with higher average levels of SWB in the population (e.g. Boarini et al., 2013; O'Connor, 2017). Indeed there are other factors that may explain the variability of patterns. For example, culture may shape individuals' preferences in such a way that they tend to identify the stage of life where they experienced events that are normative for their culture as the happiest period in life. Disentangling the influence of these and other channels constitutes an interesting avenue for future research.

\section{Conclusions}

There is no perfect measure of subjective well-being. Each measure embodies distinct information and comes with its own drawbacks (Frijters et al., 2020; Stone \& Krueger, 2018). It is therefore necessary to explore alternative indicators to fully understand the processes that drive individuals' welfare.

This paper has explored the informational content of older Europeans' memories on their happiest period in life to address - using a new approach — an old question: How does happiness evolve with age? The analysis exploits retrospective information elicited from a sample of Europeans aged 50 or older. After reshaping the data into a life panel that spans from respondents' childhood to the moment of the interview, I find that the probability of achieving the happiest period in life evolves systematically with age. The probability increases sharply from childhood to the ages of 30-34, when it reaches the maximum. At this point it is important to remark that individuals' happiest periods are long on average: for half of respondents this period lasts two decades or longer. Therefore, a more precise reading of the previous finding is that the early 30 s is the stage of life with the highest chances of belonging to the happiest period in life, though the probability also remains relatively high at adjacent ages and declines as individuals grow older. The best years in life are strongly explained, on average, by changing personal and family circumstances that are defined throughout young adulthood. Controlling for these and other contextual experiences reduces the age differentials sizably but preserves the pattern.

Retrospectively, individuals recall the decade between the mid-40s and mid-50s (usually identified as the nadir of happiness) as neither the most nor the least likely happiest ages in life. This finding does not contradict the existence a "midlife crisis" because, in fact, the probability of living the happiest period in life decreases at those ages. Yet the age gradient changes across cohorts. In particular, respondents from the younger cohort perceive lower declines in the probability of achieving their happiest period at midlife-with respect to ages at which this probability peaks - than do respondents from older cohorts who judge that life stage from later ages. In other words, individuals who grew up or were already adults through war and postwar periods display higher variability in the probability of living the happiest period in life than do individuals who grew up during more prosperous decades. 


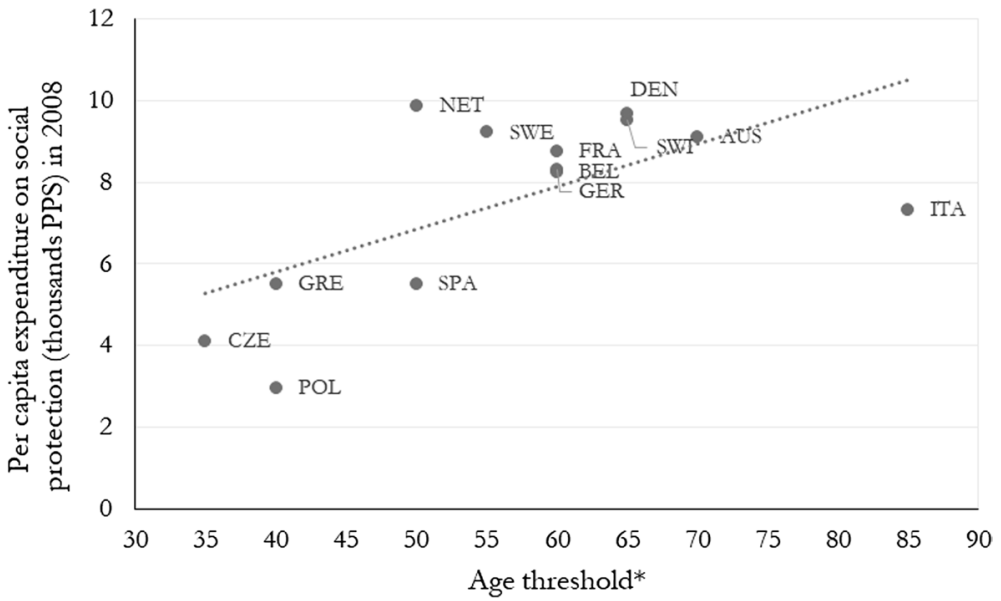

Fig. 9 Welfare state and age threshold for minimal probability of living a happiest year in life. (Eurostat and own estimations. Age threshold refers to the age at which the probability of living a happiest period in life becomes statistically similar to the probability of doing so in childhood. Note that, for Italy, the threshold exceeds the age range in the sample because at 80 the probability of living a happiest year in life remains (statistically) above the probability at the ages of 10-14)

After midlife, the average probability of living a happiest period in life does not experience any significant recovery. More specifically, the estimates show cross-country heterogeneity in the happiness trajectories between midlife and the oldest ages recalled by older individuals. A complementary exploration reveals that, in countries with stronger welfare states, individuals' probability of living the happiest period declines more slowly with age than it does in countries with weaker welfare states.

Overall, the results presented in this paper-and, in particular, the comparison with studies based on individuals' reports of current levels of happiness or life satisfactionsupport the idea that individuals' judgements of their own SWB depend on the reference they use for comparisons and may experience some systematic revision over time. An advantage of life retrospective accounts on the happiest period in life is that individuals use the same reference across all periods, which facilitates the identification of withinindividual changes in happiness. However, reports on the past may be distorted by recall and cognitive biases, especially when the time lapse is large. In addition, it is difficult to disentangle whether individuals' recall of the happiest period in life reflects an accurate emotional recall of what they lived or, as Easterlin (2002) states, it rather indicates the happiness status that, according to present preferences, individuals should have had, given the restrictions and circumstances they faced in the past. If Easterlin's statement is true, then previous findings would inform us about how respondents perceive ageing. From this perspective, we should infer that older people elaborate their life trajectory of happiness as an inverted-U curve that decreases from 30 to 34 onward. Even though individuals in their late 60s and 70s may not consider themselves unhappy at present (as the U-curve of happiness implies), in retrospect, they judge this stage of life as having a low probability of being the happiest in life.

Is this information interesting from a policy point of view? The ageing process in Europe has increased the relevance of older people in policy-makers agenda. Exploring how they remember the past and how they associate subjective well-being to different 
circumstances may help to understand their present decisions and policy preferences (Pudney, 2011). Older people tend to support policies related to their own position in the life cycle-higher spending on pensions and health care-over policies that would benefit younger generations, like education or protecting the environment (De Mello et al. 2017). The findings shown in this paper suggest that these welfare state preferences cohere with the life cycle pattern of happiness presented above and, in particular, with the perceived shrinking of well-being at older ages.

Despite the large body of literature on the life-cycle pattern of SWB, new avenues remain open to contribute to this issue through alternative approaches, data and measures. This paper has illustrated the potential of retrospective surveys such as SHARELIFE for exploring the events and circumstances that have shaped the well-being of the oldest European generations.

\section{Appendix A}

See Tables 1,2,3,4.

Table 1 Share of respondents who report a happiest period and median spell duration, in years (for those who report it) by gender and country

\begin{tabular}{|c|c|c|c|}
\hline & Share & Median & No. respondents \\
\hline \multicolumn{4}{|l|}{ Country } \\
\hline Austria & 0.40 & 20 & 526 \\
\hline Belgium & 0.42 & 19 & 1,967 \\
\hline Czech Rep & 0.51 & 26 & 1,327 \\
\hline Denmark & 0.36 & 14 & 1,158 \\
\hline France & 0.74 & 30 & 1,206 \\
\hline Germany & 0.40 & 13 & 1,186 \\
\hline Greece & 0.40 & 25 & 2,131 \\
\hline Italy & 0.48 & 10 & 1,956 \\
\hline Netherlands & 0.30 & 20 & 1,443 \\
\hline Poland & 0.42 & 20 & 1,245 \\
\hline Spain & 0.49 & 30 & 1,296 \\
\hline Sweden & 0.48 & 22 & 1,126 \\
\hline Switzerland & 0.37 & 15 & 755 \\
\hline \multicolumn{4}{|l|}{ Gender } \\
\hline Men & 0.39 & 21 & 7,514 \\
\hline Women & 0.48 & 20 & 9,808 \\
\hline \multicolumn{4}{|l|}{ Birth cohort } \\
\hline $1928-38$ & 0.41 & 28 & 4,746 \\
\hline $1939-48$ & 0.45 & 19 & 6,772 \\
\hline $1949-58$ & 0.46 & 15 & 5,804 \\
\hline Total & 0.44 & 21 & 17,322 \\
\hline
\end{tabular}

Source: SHARELIFE, 2008-09. The sample is composed respondents aged 50-80 who met all selection criteria described in Sect. 3 
Table 2 Personal circumstances, family/life events and context over the life course (means for continuous variables; percentages for binary variables)

\begin{tabular}{lrrrrrrrr}
\hline & $0-9$ & $10-19$ & $20-29$ & $30-39$ & $40-49$ & $50-59$ & $60-69$ & $70+$ \\
\hline Socio-demographic characteristics & & & & & & & & \\
Cohabiting with partner & 0.0 & 10.9 & 85.5 & 93.6 & 92.8 & 89.6 & 85.4 & 76.0 \\
Number of children (mean) & 0.0 & 0.0 & 0.6 & 1.8 & 2.0 & 2.01 & 2.2 & 2.3 \\
Years of education (mean) & 1.5 & 8.3 & 11.0 & 11.2 & 11.2 & 11.0 & 10.1 & 9.2 \\
In education & 88.1 & 85.5 & 18.9 & 0.7 & 0.1 & 0.0 & 0.0 & 0.0 \\
Working spell & 0.2 & 59.7 & 86.7 & 81.2 & 80.8 & 75.3 & 43.8 & 3.0 \\
Unemployment spell & 0.0 & 3.2 & 2.9 & 2.0 & 2.9 & 4.9 & 3.3 & 1.1 \\
Retirement spell & 0.0 & 0.0 & 0.2 & 0.7 & 2.8 & 20.4 & 69.5 & 79.0 \\
Other inactive status & 99.9 & 34.3 & 42.1 & 30.0 & 25.7 & 30.3 & 32.9 & 20.5 \\
Family/life events & & & & & & & & \\
Start own household & 0.0 & 17.0 & 71.2 & 7.9 & 1.3 & 0.4 & 0.2 & 0.0 \\
Child birth & 0.0 & 5.2 & 69.6 & 49.3 & 1.0 & 0.4 & 0.1 & 0.0 \\
Death of partner & 0.0 & 0.0 & 0.3 & 1.0 & 2.0 & 3.9 & 5.7 & 7.3 \\
Death of a child & 0.0 & 0.0 & 0.0 & 1.6 & 1.2 & 0.9 & 1.1 & 1.6 \\
Illness & 1.0 & 1.6 & 3.3 & 6.7 & 12.7 & 20.8 & 24.2 & 29.6 \\
Financial hardship & 1.3 & 3.4 & 12.6 & 14.9 & 12.8 & 10.9 & 7.4 & 5.5 \\
Stress & 0.5 & 2.3 & 9.6 & 17.0 & 23.0 & 25.0 & 18.5 & 13.0 \\
Hunger & 4.1 & 4.1 & 0.8 & 0.3 & 0.2 & 0.1 & 0.1 & 0.0 \\
Dispossessed due to persecution & 1.1 & 0.8 & 0.1 & 0.0 & 0.0 & 0.0 & 0.0 & 0.0 \\
Institutionalized & 0.8 & 1.3 & 1.1 & 0.4 & 0.3 & 0.2 & 0.3 & 0.5 \\
Country context & & & & & & & & \\
War & 38.5 & 15.3 & 0.4 & 0.0 & 0.0 & 0.0 & 0.0 & 0.0 \\
\hline
\end{tabular}

The sample consists of 17,322 men and women aged 50-80 at the time of the interview

Source: SHARELIFE 2008-2009. The variable "Institutionalized" refers to living in orphanage, prison, labor/concentration camps, mental hospitals or nursing homes for the elderly 


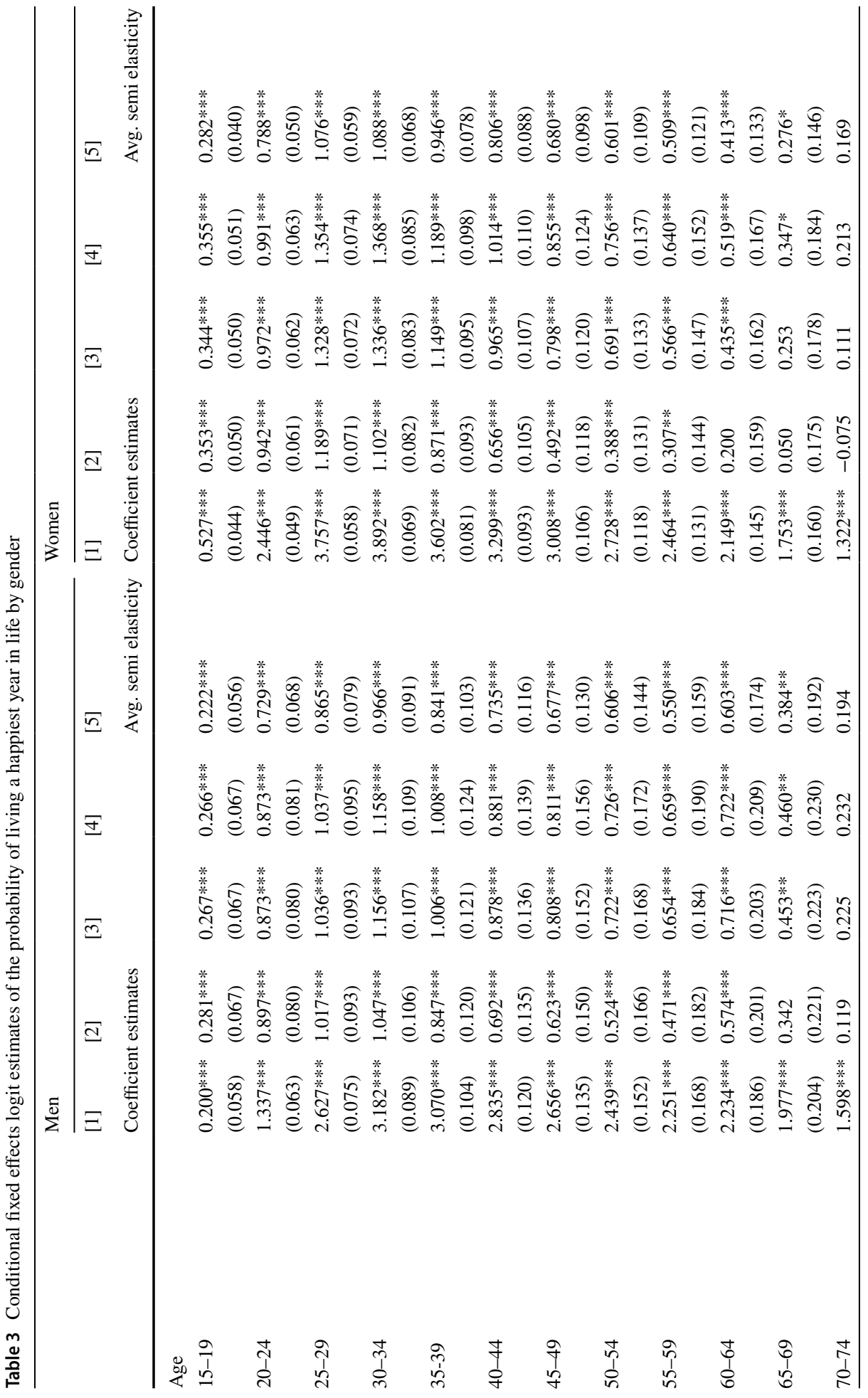




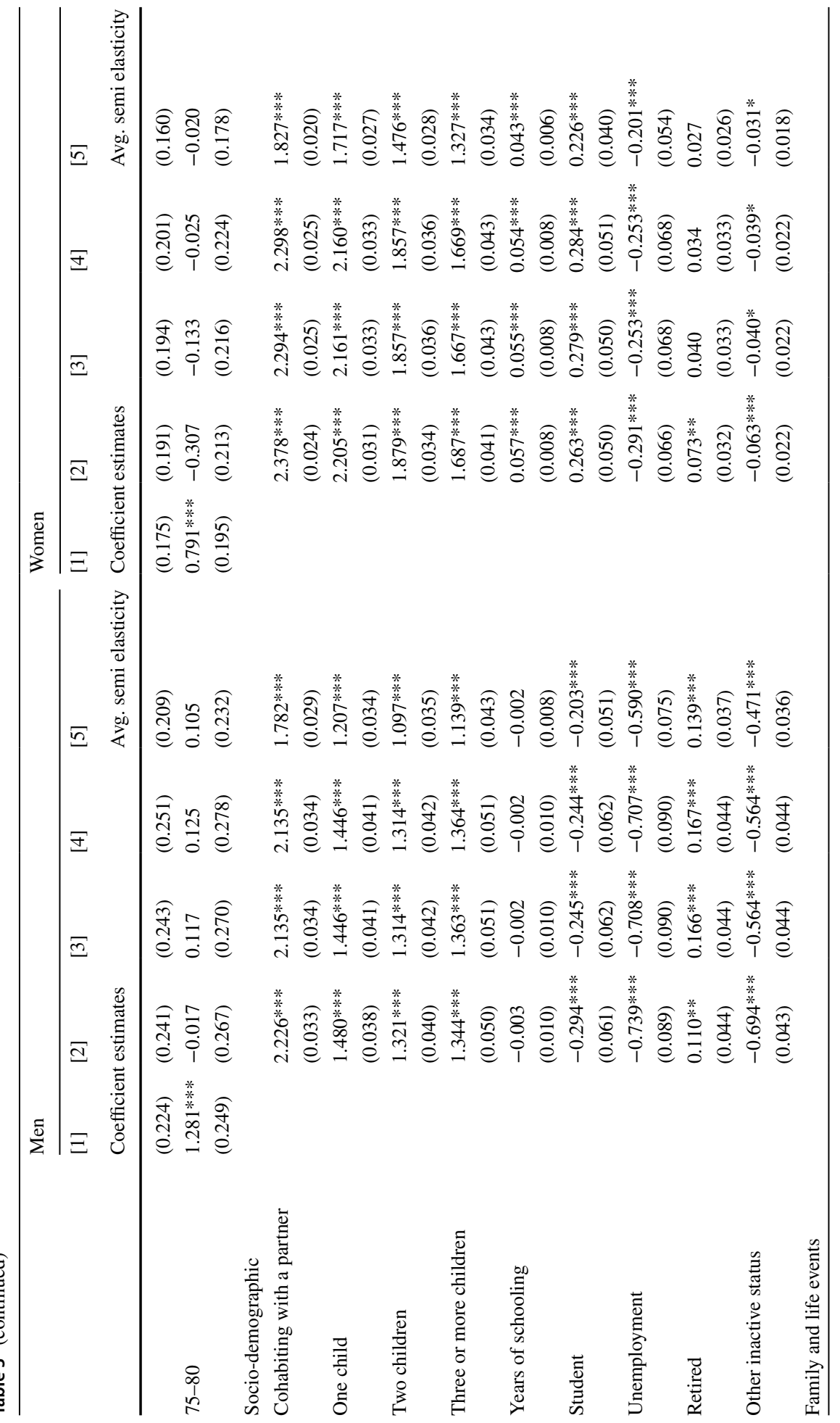




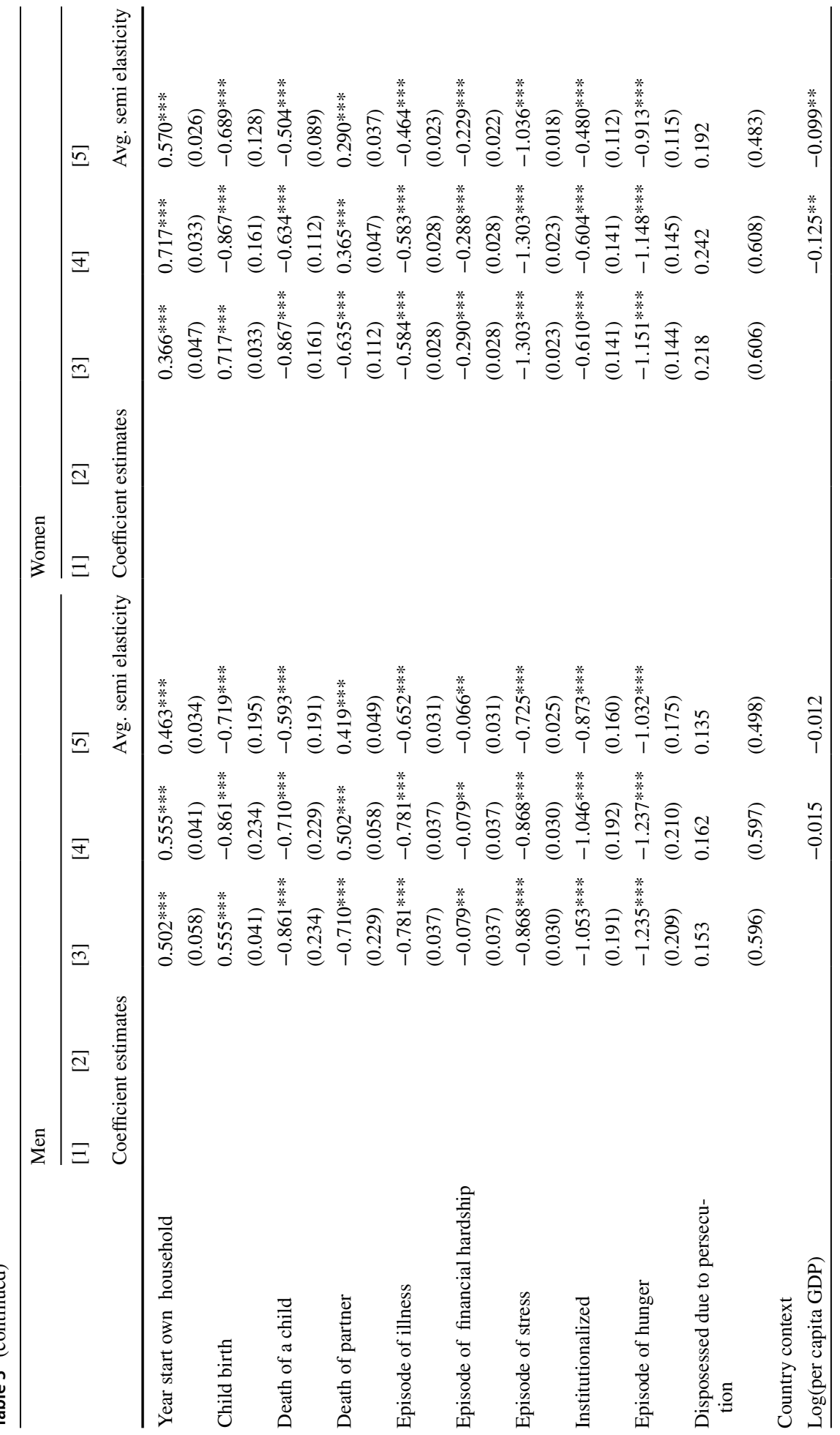




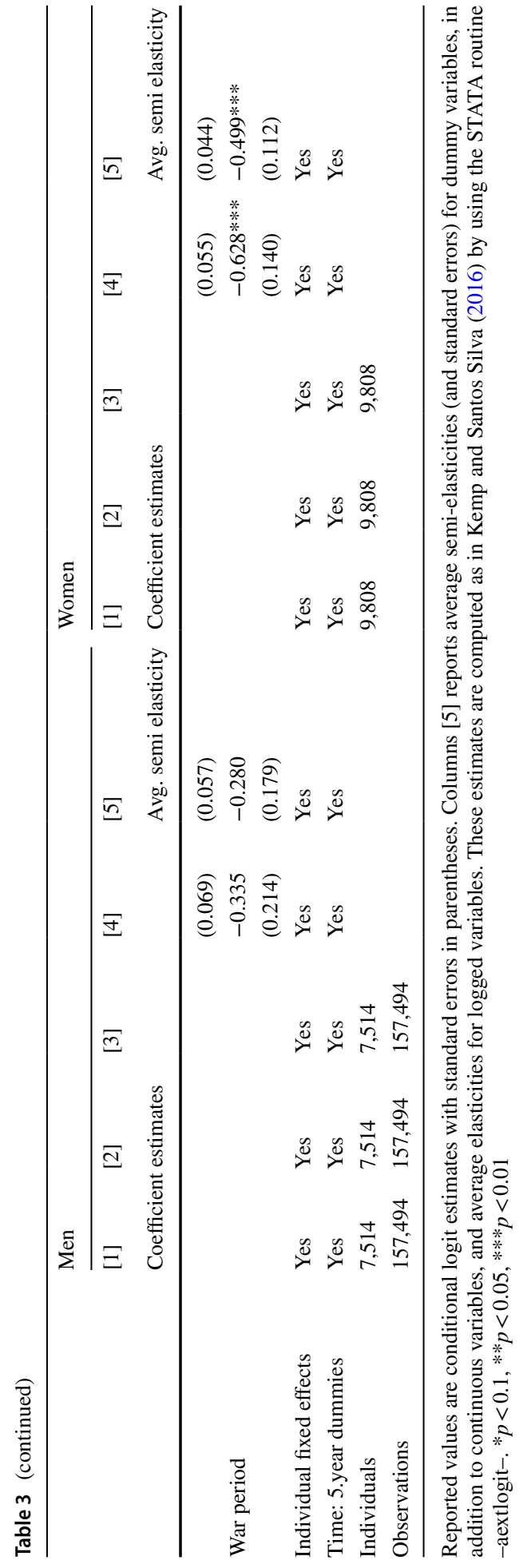

글 Springer 
Table 4 Conditional fixed effects logit estimates of the probability of living a happiest year in life by birth cohort (average semi-elasticities)

\begin{tabular}{|c|c|c|c|}
\hline & \multicolumn{3}{|l|}{ Birth cohort } \\
\hline & $1928-1938$ & 1938-1948 & $>1949$ \\
\hline \multicolumn{4}{|l|}{ Age (ref. 10-14) } \\
\hline $15-19$ & $\begin{array}{l}0.431 * * * \\
(0.076)\end{array}$ & $\begin{array}{l}0.355 * * * \\
(0.059)\end{array}$ & $\begin{array}{l}0.153 * * \\
(0.063)\end{array}$ \\
\hline $20-24$ & $\begin{array}{l}1.002 * * * \\
(0.094)\end{array}$ & $\begin{array}{l}0.899 * * * \\
(0.075)\end{array}$ & $\begin{array}{l}0.614 * * * \\
(0.082)\end{array}$ \\
\hline $25-29$ & $\begin{array}{l}1.163 * * * \\
(0.108)\end{array}$ & $\begin{array}{l}1.113 * * * \\
(0.087)\end{array}$ & $\begin{array}{l}0.866^{* * * *} \\
(0.096)\end{array}$ \\
\hline $30-34$ & $\begin{array}{l}1.225 * * * \\
(0.120)\end{array}$ & $\begin{array}{l}1.141 * * * \\
(0.097)\end{array}$ & $\begin{array}{l}0.820 * * * \\
(0.109)\end{array}$ \\
\hline $35-39$ & $\begin{array}{l}1.089 * * * \\
(0.132)\end{array}$ & $\begin{array}{l}0.948 * * * \\
(0.107)\end{array}$ & $\begin{array}{l}0.725 * * * \\
(0.122)\end{array}$ \\
\hline $40-44$ & $\begin{array}{l}0.885 * * * \\
(0.145)\end{array}$ & $\begin{array}{l}0.802 * * * \\
(0.118)\end{array}$ & $\begin{array}{l}0.648 * * * \\
(0.135)\end{array}$ \\
\hline $45-49$ & $\begin{array}{l}0.691 * * * \\
(0.158)\end{array}$ & $\begin{array}{l}0.687 * * * \\
(0.129)\end{array}$ & $\begin{array}{l}0.594 * * * \\
(0.149)\end{array}$ \\
\hline $50-54$ & $\begin{array}{l}0.579 * * * \\
(0.171)\end{array}$ & $\begin{array}{l}0.625 * * * \\
(0.141)\end{array}$ & $\begin{array}{l}0.526 * * * \\
(0.163)\end{array}$ \\
\hline $55-59$ & $\begin{array}{l}0.523 * * * \\
(0.185)\end{array}$ & $\begin{array}{l}0.599 * * * \\
(0.153)\end{array}$ & $\begin{array}{l}0.358 * * \\
(0.180)\end{array}$ \\
\hline $60-64$ & $\begin{array}{l}0.478 * * \\
(0.199)\end{array}$ & $\begin{array}{l}0.562 * * * \\
(0.166)\end{array}$ & \\
\hline $65-69$ & $\begin{array}{l}0.332 \\
(0.214)\end{array}$ & $\begin{array}{l}0.432 * * \\
(0.183)\end{array}$ & \\
\hline $70-74$ & $\begin{array}{l}0.237 \\
(0.229)\end{array}$ & & \\
\hline $75-80$ & $\begin{array}{l}0.117 \\
(0.247)\end{array}$ & & \\
\hline \multicolumn{4}{|l|}{ Socio-demographic } \\
\hline Cohabiting with a partner & $\begin{array}{l}2.122 * * * \\
(0.031)\end{array}$ & $\begin{array}{l}1.816 * * * \\
(0.025)\end{array}$ & $\begin{array}{l}1.628 * * * \\
(0.028)\end{array}$ \\
\hline One child & $\begin{array}{l}1.490 * * * \\
(0.042)\end{array}$ & $\begin{array}{l}1.452 * * * \\
(0.033)\end{array}$ & $\begin{array}{l}1.609 * * * \\
(0.035)\end{array}$ \\
\hline Two children & $\begin{array}{l}1.249 * * * \\
(0.044)\end{array}$ & $\begin{array}{l}1.346 * * * \\
(0.035)\end{array}$ & $\begin{array}{l}1.393 * * * \\
(0.037)\end{array}$ \\
\hline Three or more children & $\begin{array}{l}1.131 * * * \\
(0.051)\end{array}$ & $\begin{array}{l}1.294 * * * \\
(0.043)\end{array}$ & $\begin{array}{l}1.350 * * * \\
(0.046)\end{array}$ \\
\hline Years of schooling & $\begin{array}{l}0.023 * \\
(0.012)\end{array}$ & $\begin{array}{l}0.049 * * * \\
(0.008)\end{array}$ & $\begin{array}{l}0.008 \\
(0.008)\end{array}$ \\
\hline Student & $\begin{array}{l}0.387 * * * \\
(0.072)\end{array}$ & $\begin{array}{l}0.066 \\
(0.051)\end{array}$ & $\begin{array}{l}-0.099 * * \\
(0.049)\end{array}$ \\
\hline Unemployment & $\begin{array}{l}-0.121 \\
(0.103)\end{array}$ & $\begin{array}{l}-0.366 * * * \\
(0.072)\end{array}$ & $\begin{array}{l}-0.356^{* * *} \\
(0.065)\end{array}$ \\
\hline
\end{tabular}


Table 4 (continued)

\begin{tabular}{|c|c|c|c|c|}
\hline & & Birth cohort & & \\
\hline & & 1928-1938 & 1938-1948 & $>1949$ \\
\hline Retired & & $\begin{array}{l}0.220 * * * \\
(0.033)\end{array}$ & $\begin{array}{l}0.062 * * \\
(0.031)\end{array}$ & $\begin{array}{l}-0.073 \\
(0.062)\end{array}$ \\
\hline Other inactive status & & $\begin{array}{l}-0.070 * * \\
(0.028)\end{array}$ & $\begin{array}{l}-0.143 * * * \\
(0.025)\end{array}$ & $\begin{array}{l}0.011 \\
(0.029)\end{array}$ \\
\hline Family and life events & & & & \\
\hline Year start own household & & $\begin{array}{l}0.429 * * * \\
(0.061)\end{array}$ & $\begin{array}{l}0.306 * * * \\
(0.047)\end{array}$ & $\begin{array}{l}0.259 * * * \\
(0.049)\end{array}$ \\
\hline Child birth & & $\begin{array}{l}0.485 * * * \\
(0.041)\end{array}$ & $\begin{array}{l}0.498 * * * \\
(0.033)\end{array}$ & $\begin{array}{l}0.592 * * * \\
(0.036)\end{array}$ \\
\hline Death of a child & & $\begin{array}{l}-0.643 * * * \\
(0.163)\end{array}$ & $\begin{array}{l}-0.897 * * * \\
(0.189)\end{array}$ & $\begin{array}{l}-0.500^{* * *} \\
(0.229)\end{array}$ \\
\hline Death of partner & & $\begin{array}{l}-0.250 * * \\
(0.114)\end{array}$ & $\begin{array}{l}-0.735 * * * \\
(0.140)\end{array}$ & $\begin{array}{l}-0.758 * * * \\
(0.225)\end{array}$ \\
\hline Episode of illness & & $\begin{array}{l}-0.739 * * * \\
(0.033)\end{array}$ & $\begin{array}{l}-0.398 * * * \\
(0.028)\end{array}$ & $\begin{array}{l}-0.532 \text { *** } \\
(0.036)\end{array}$ \\
\hline Episode of financial hardship & $\begin{array}{l}-0.167 * * * \\
(0.034)\end{array}$ & & $\begin{array}{l}-0.097 * * * \\
(0.029)\end{array}$ & $\begin{array}{l}-0.280^{* * * *} \\
(0.031)\end{array}$ \\
\hline Episode of stress & $\begin{array}{l}-0.978^{* * * *} \\
(0.029)\end{array}$ & & $\begin{array}{l}-0.942 * * * \\
(0.023)\end{array}$ & $\begin{array}{l}-0.879 \text { *** } \\
(0.026)\end{array}$ \\
\hline Institutionalized & $\begin{array}{l}-0.406^{* *} \\
(0.165)\end{array}$ & & $\begin{array}{l}-0.646 * * * \\
(0.140)\end{array}$ & $\begin{array}{l}-0.763 \text { *** } \\
(0.179)\end{array}$ \\
\hline Episode of hunger & $\begin{array}{l}-0.447 * * * \\
(0.131)\end{array}$ & & $\begin{array}{l}-1.566^{* * * *} \\
(0.172)\end{array}$ & $\begin{array}{l}-1.075^{* * * *} \\
(0.223)\end{array}$ \\
\hline Disposessed due to persecution & $\begin{array}{l}0.573 \\
(0.417)\end{array}$ & & $\begin{array}{l}-0.438 \\
(0.687)\end{array}$ & $\begin{array}{l}-9.150 \\
(377.973)\end{array}$ \\
\hline Country context & & & & \\
\hline Log(per capita GDP) & $\begin{array}{l}0.212 * * * \\
(0.058)\end{array}$ & & $\begin{array}{l}-0.202^{* * *} \\
(0.057)\end{array}$ & $\begin{array}{l}-0.199 \text { *** } \\
(0.070)\end{array}$ \\
\hline War period & $\begin{array}{l}-0.330 * * * \\
(0.097)\end{array}$ & & $\begin{array}{l}-10.642 \\
(343.286)\end{array}$ & \\
\hline Individual fixed effects & Yes & & Yes & Yes \\
\hline Time: 5.year dummies & Yes & & Yes & Yes \\
\hline Individuals & 4,746 & & 6,772 & 5,804 \\
\hline $\mathrm{N}$ & 310,478 & & 373,806 & 269,760 \\
\hline
\end{tabular}

Reported values are conditional logit estimates with standard errors in parentheses. Columns [5] reports average semi-elasticities for dummy variables, in addition to continuous variables and average elasticities for logged variables, computed as in Kemp and Santos Silva (2016) by using the STATA routine -aextlogit-. ${ }^{*} p<0.1,{ }^{*} p<0.05,{ }^{* * *} p<0.01$

See Fig. 10. 


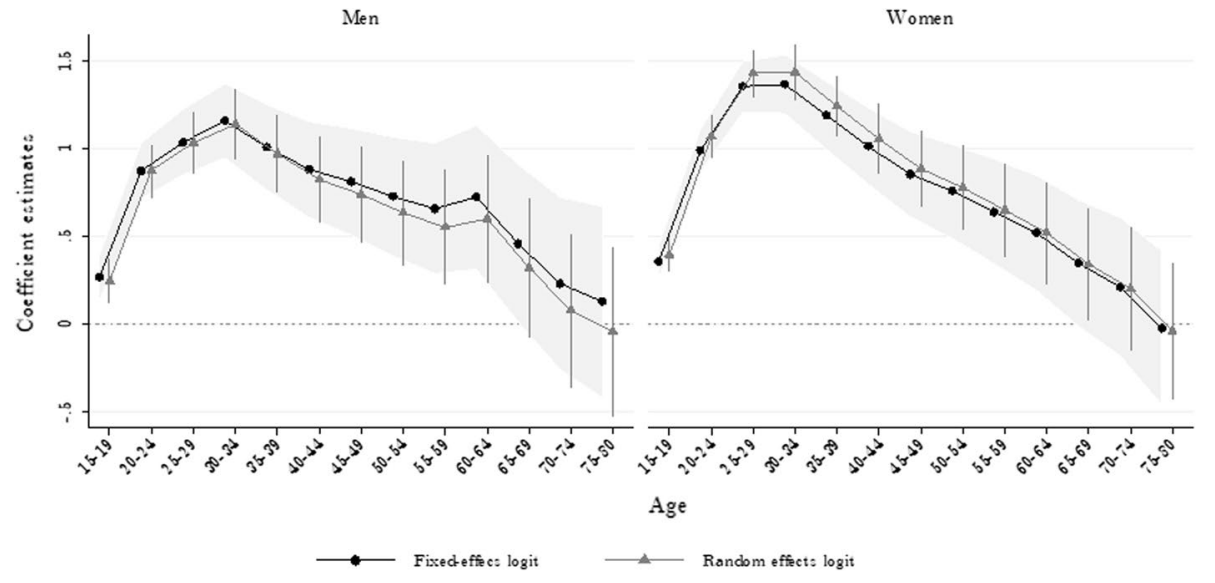

Fig. 10 Conditional fixed effects logit vs. random effects logit. (Graphs plot coefficient estimates and 95\% confidence intervals (grey area for fixed effects logit estimates). The dependent variable is the individual's probability of identifying a year as one of the happiest in life. The set of added controls corresponds to specification [4] of Appendix Table 3)

\section{Appendix B}

See Table 5. 
Table 5 Probit estimates of the probability of reporting a distinct period of happiness: Average marginal effects (AME)

\begin{tabular}{|c|c|c|c|c|c|c|}
\hline & \multicolumn{2}{|l|}{ All } & \multicolumn{2}{|l|}{ Men } & \multicolumn{2}{|l|}{ Women } \\
\hline & AME & s.e & $\mathrm{AME}$ & s.e & AME & s.e \\
\hline \multicolumn{7}{|l|}{ Current socio-demographic characteristics } \\
\hline Age & $-0.002 * * *$ & 0.001 & -0.001 & 0.001 & $-0.003^{* *}$ & 0.001 \\
\hline Female & $0.048 * * *$ & 0.008 & & & & \\
\hline Has children & $0.049 * *$ & 0.015 & 0.018 & 0.020 & $0.081 * * *$ & 0.019 \\
\hline Education (ISCED: 7 levels) & $0.015^{* *}$ & 0.003 & $0.017 * * *$ & 0.004 & $0.013 * * *$ & 0.004 \\
\hline Unemployed & -0.011 & 0.035 & 0.002 & 0.042 & -0.024 & 0.051 \\
\hline Retired & 0.013 & 0.022 & -0.018 & 0.025 & 0.030 & 0.027 \\
\hline Other inactive & 0.038 & 0.019 & $0.081 *$ & 0.047 & $0.037 * *$ & 0.019 \\
\hline Cohabiting with partner & -0.017 & 0.021 & -0.013 & 0.029 & -0.019 & 0.020 \\
\hline Current illness episode & $0.092 * * *$ & 0.019 & $0.092 * * *$ & 0.021 & 0.007 & 0.005 \\
\hline \multicolumn{7}{|l|}{ Subjective variables } \\
\hline Always find ways to solve problems (1 to 5) & -0.002 & 0.007 & 0.004 & 0.012 & $0.009 *$ & 0.005 \\
\hline Always optimist about future (1 to 5) & 0.009 & 0.007 & 0.007 & 0.010 & -0.005 & 0.007 \\
\hline Current life satisfaction (0 to 10 ) & 0.004 & 0.006 & -0.001 & 0.009 & 0.007 & 0.008 \\
\hline \multicolumn{7}{|l|}{ Life events } \\
\hline Past episode of illness & $0.102 * * *$ & 0.010 & $0.108 * * *$ & 0.014 & $0.089 * * *$ & 0.018 \\
\hline Ever divorced & $0.073 * *$ & 0.030 & $0.061^{*}$ & 0.032 & $0.083 * *$ & 0.033 \\
\hline Death of partner & $0.075 * * *$ & 0.020 & $0.099 * * *$ & 0.030 & $0.067 * * *$ & 0.026 \\
\hline Ever institutionalized & 0.049 & 0.031 & 0.080 & 0.050 & 0.018 & 0.045 \\
\hline Ever unemployed & -0.003 & 0.018 & $0.029 *$ & 0.017 & -0.035 & 0.032 \\
\hline Ever in financial hardship & $0.095^{* * *}$ & 0.011 & $0.108 * * *$ & 0.015 & $0.082 * * *$ & 0.014 \\
\hline Ever in stress episode & $0.195 * * *$ & 0.018 & $0.171 * * *$ & 0.015 & $0.213 * * *$ & 0.024 \\
\hline Ever in hunger & 0.020 & 0.021 & 0.009 & 0.025 & 0.028 & 0.033 \\
\hline Ever dispossessed & 0.004 & 0.026 & 0.012 & 0.030 & -0.003 & 0.035 \\
\hline Lived in war country & -0.001 & 0.018 & 0.019 & 0.022 & -0.015 & 0.028 \\
\hline Lived in absence of democracy & -0.020 & 0.032 & $-0.046^{* *}$ & 0.020 & 0.001 & 0.043 \\
\hline \multicolumn{7}{|l|}{ Country (ref: France) } \\
\hline Austria & $-0.363 * * *$ & 0.025 & $-0.362 * * *$ & 0.017 & $-0.359 * * *$ & 0.031 \\
\hline Germany & $-0.375^{* * *}$ & 0.013 & $-0.376^{* * *}$ & 0.011 & $-0.377 * * *$ & 0.017 \\
\hline Sweden & $-0.252 * * *$ & 0.024 & $-0.256^{* * *}$ & 0.019 & $-0.252 * * *$ & 0.030 \\
\hline Netherlands & $-0.430 * * *$ & 0.021 & $-0.460 * * *$ & 0.012 & $-0.407 * * *$ & 0.027 \\
\hline Spain & $-0.135 * * *$ & 0.016 & $-0.140 * * *$ & 0.009 & $-0.133 * * *$ & 0.026 \\
\hline Italy & $-0.209 * * *$ & 0.023 & $-0.210 * * *$ & 0.015 & $-0.211^{* * *}$ & 0.028 \\
\hline Denmark & $-0.384 * * *$ & 0.021 & $-0.449 * * *$ & 0.010 & $-0.337 * * *$ & 0.030 \\
\hline Greece & $-0.262 * * *$ & 0.015 & $-0.239 * * *$ & 0.013 & $-0.274 * * *$ & 0.022 \\
\hline Switzerland & $-0.390 * * *$ & 0.022 & $-0.417 * * *$ & 0.017 & $-0.363^{* * *}$ & 0.028 \\
\hline Belgium & $-0.335 * * *$ & 0.022 & $-0.371 * * *$ & 0.014 & $-0.303^{* * *} *$ & 0.028 \\
\hline Czechia & $-0.167 * * *$ & 0.009 & $-0.166^{* * *}$ & 0.010 & $-0.169 * * *$ & 0.015 \\
\hline Poland & $-0.294 * * *$ & 0.010 & $-0.279 * * *$ & 0.009 & $-0.318^{* * *}$ & 0.018 \\
\hline$N$ & 10,013 & 4,357 & 5,656 & & & \\
\hline
\end{tabular}

Robust standard errors clustered at country level in parentheses. $* p<0.1 ; * * p<0.05 ; * * * p<0.01$ 


\section{Who does identify a happiest period in life?}

To identify which factors correlate with the identification of a distinct period of happiness in life, I exploit the original cross-sectional structure of SHARELIFE to model respondents' likelihood of reporting (or not) a distinct period of happiness. Table 5 reports probit estimates for the full sample and for men and women separately. The set of explanatory variables includes three sets of explanatory variables. First, I consider individuals' characteristics at the time of interview-including age, gender, labor status, educational attainment, and dummy variables for cohabitation with a partner, having children, illness, and country of residence. Second, we add indicators for whether the respondent faced any of the following events over her life: divorce, death of a partner, institutionalization, unemployment, stress, hunger, dispossession, exposure to war, and/or absence of democracy in the country of residence at some point in life. Our third set of explanatory variables includes the current level of life satisfaction, as reported by each respondent, and two variables intended to measure her optimism/pessimism. Life satisfaction is elicited by SHARE's core questionnaire'; the other two variables are based on responses to the "dropoff" questionnaire. The latter variables measure (on a scale from 1 to 5) each respondent's level of agreement with the following statements: (a) "I still find ways to solve a problem if others have given up"; and (b) "I'm always optimistic about my future". Since the drop-off questionnaire's response rate is low and since it is completed by individuals in the main SHARE sample, the sample size for estimation is limited to the 10,013 individuals who responded to the relevant variables for the analysis.

Results indicate that the probability of reporting a salient period of happiness in life is higher for women than for men, decreases significantly with age (although this effect is significant only for women), increases with education level, and exhibits a positive relation both to cohabitation with a partner and to having children. With regard to life events, our estimates indicate that individuals who have suffered from personal negative events (such as illness, stress, hunger, and/or financial hardship), which likely depressed their happiness levels at some time in their lives, are more likely to identify a distinct period of highest happiness. It is interesting that neither current life satisfaction of respondents nor their level of optimism is statistically significant. Taken together, these findings suggest that it is what happens to individuals across life (life events, changing family circumstances, etc.) rather than their personality traits - that leads them to identify a distinct period of happiness. This evidence reduces but does not entirely eliminate our concern that individuals who report a happiest period in life may differ significantly, in terms of personality traits, from other individuals in the sample.

Funding Open Access funding provided thanks to Universidade de Vigo/CISUG, in the framework of the CRUE-CSIC agreement with Springer Nature. The author acknowledges financial support from the Spanish Ministerio de Ciencia, Innovación y Universidades and FEDER through Grant RTI-2018-099403-B-I00.

Open Access This article is licensed under a Creative Commons Attribution 4.0 International License, which permits use, sharing, adaptation, distribution and reproduction in any medium or format, as long as you give appropriate credit to the original author(s) and the source, provide a link to the Creative Commons licence, and indicate if changes were made. The images or other third party material in this article

\footnotetext{
${ }^{9}$ I linked data from SHARELIFE to basic demographic data from the first wave of SHARE carried out in 2004/2005 (2006/2007 for the Czech Republic and Poland).
} 
are included in the article's Creative Commons licence, unless indicated otherwise in a credit line to the material. If material is not included in the article's Creative Commons licence and your intended use is not permitted by statutory regulation or exceeds the permitted use, you will need to obtain permission directly from the copyright holder. To view a copy of this licence, visit http://creativecommons.org/licenses/by/4.0/.

\section{References}

Antonova, L., Aranda, L., Pasini, G., and Trevisan, E. (2014). Migration, family history and pension: the second release of the SHARE Job Episodes Panel. Working Paper Series, 18.

Blanchflower, D. G. (2020). Is happiness U-shaped everywhere? Age and subjective well-being in 145 countries. Journal of Population Economics, 34, 575-624.

Blanchflower, D. G., \& Oswald, A. J. (2004). Well-being over time in Britain and the USA. Journal of Public Economics, 88(7-8), 1359-1386.

Blanchflower, D. G., \& Oswald, A. J. (2008). Is well-being U-shaped over the life cycle? Social Science \& Medicine, 66(8), 1733-1749.

Blanchflower, D. G., \& Oswald, A. J. (2016). Antidepressants and age: A new form of evidence for U-shaped well-being through life. Journal of Economic Behavior \& Organization, 127, 46-58.

Blanchflower, D. G., \& Oswald, A. J. (2019). Do humans suffer a psychological low in midlife? Two approaches (with and without controls) in seven data sets In The economics of happiness (pp. 439453). Cham: Springer.

Boarini, R., Comola, M., de Keulenaer, F., Manchin, R., \& Smith, C. (2013). Can governments boost people's sense of well-being? The impact of selected labour market and health policies on life satisfaction. Social Indicators Research, 114(1), 105-120.

Bolt, J., Inklaar, R., de Jong, H., and van Zanden, J. (2018). Maddison project database, version 2018. Rebasing 'Maddison': new income comparisons and the shape of long-run economic development.

Börsch-Supan, A., Brandt, M., Hunkler, C., Kneip, T., Korbmacher, J., Malter, F., Schaan, B., Stuck, S., \& Zuber, S. (2013). Data resource profile: The survey of health, ageing and retirement in Europe (SHARE). International Journal of Epidemiology, 42(4), 992-1001.

Brugiavini, A., Cavapozzi, D., Pasini, G., and Trevisan, E. (2013). Working life histories from SHARELIFE: a retrospective panel. SHARE WP Series, 11-13.

Chamberlain, G. (1984). Panel data, in Z. Griliches and M.D. Intriligator (Eds.), Handbook of Econometrics, Amsterdam: North Holland, 2, 1247-1318.

Cheng, T. C., Powdthavee, N., \& Oswald, A. J. (2017). Longitudinal evidence for a midlife nadir in human well-being: Results from four data sets. The Economic Journal, 127(599), 126-142.

Clark, A. E., and Oswald, A. J. (2006). The curved relationship between SWB and age. Paris-Jourdan Sciences Economiques, Discussion Paper No. 2006-29.

Clark, A. E., d'Albis, H., and Greulich, A. (2020). The Age U-shape in Europe: The Protective Role of Partnership (Ref: halshs-02872212).

Clark, A. E., \& Oswald, A. J. (1994). Unhappiness and unemployment. The Economic Journal, 104(424), 648-659.

Clark, A. E. (2019). Born to be mild? Cohort effects don't (fully) explain why well-being is U-shaped in age. In The economics of happiness (pp. 387-408). Springer, Cham.

De Mello, L., Schotte, S., Tiongson, E. R., \& Winkler, H. (2017). Greying the budget: Ageing and preferences over public policies. Kyklos, 70(1), 70-96.

Deaton, A. (2008). Income, health, and well-being around the world: Evidence from the gallup world poll. Journal of Economic Perspectives, 22(2), 53-72.

Diener, E., \& Chan, M. Y. (2011). Happy people live longer: Subjective well-being contributes to health and longevity. Applied Psychology: Health and Well-Being, 3(1), 1-43.

Diener, E., Wirtz, D., \& Oishi, S. (2001). End effects of rated life quality: The james dean effect. Psychological Science, 12(2), 124-128.

Easterlin, R. A. (2002). Is reported happiness five years ago comparable to present happiness? A cautionary note. Journal of Happiness Studies, 3(2), 193-198.

Easterlin, R. A. (2006). Life cycle happiness and its sources: Intersections of psychology, economics, and demography. Journal of Economic Psychology, 27(4), 463-482.

Field, D. (1997). Looking back, what period of your life brought you the most satisfaction. The International Journal of Aging and Human Development, 45(3), 169-194.

Fortin, N., Helliwell, J. F., and Wang, S. (2015). How does subjective well-being vary around the world by gender and age. World Happiness Report, 42-75. 
Fredrickson, B. L., \& Kahneman, D. (1993). Duration neglect in retrospective evaluations of affective episodes. Journal of Personality and Social Psychology, 65(1), 45.

Frey, B. S., \& Stutzer, A. (2002). What can economists learn from happiness research? Journal of Economic Literature, 40(2), 402-435.

Frijters, P., \& Beatton, T. (2012). The mystery of the U-shaped relationship between happiness and age. Journal of Economic Behavior \& Organization, 82(2-3), 525-542.

Frijters, P., Clark, A. E., Krekel, C., \& Layard, R. (2020). A happy choice: Wellbeing as the goal of government. Behavioural Public Policy, 4(2), 126-165.

Galambos, N. L., Krahn, H. J., Johnson, M. D., \& Lachman, M. E. (2020). The U shape of happiness across the life course: Expanding the discussion. Perspectives on Psychological Science, 15(4), 898-912.

Garrouste, C. and O. Paccagnella (2011). Data Quality: Three examples of consistency across SHARE and SHARELIFE Data. In: M. Schröder. Retrospective Data Collection in the Survey of Health, Ageing and Retirement in Europe. SHARELIFE Methodology. Mannheim: MEA.

Glenn, N. (2009). Is the apparent U-shape of well-being over the life course a result of inappropriate use of control variables? A commentary on Blanchflower and Oswald (66: 8, 2008, 1733-1749). Social Science \& Medicine, 69(4), 481-485.

Gomez, V., Grob, A., \& Orth, U. (2013). The adaptive power of the present: Perceptions of past, present, and future life satisfaction across the life span. Journal of Research in Personality, 47(5), 626-633.

Graham, C., \& Pozuelo, J. R. (2017). Happiness, stress, and age: How the U curve varies across people and places. Journal of Population Economics, 30(1), 225-264.

Gwozdz, W., \& Sousa-Poza, A. (2010). Ageing, health and life satisfaction of the oldest old: An analysis for Germany. Social Indicators Research, 97(3), 397-417.

Havari, E. and F. Mazzonna (2011). Can we trust older people's statements on their childhood circumstances? Evidence from SHARELIFE. SHARE Working Paper (05-2011). Mannheim.

Havari, E., \& Peracchi, F. (2017). Growing up in wartime: Evidence from the era of two world wars. Economics \& Human Biology, 25, 9-32.

Kahneman, D., \& Riis, J. (2005). Living, and thinking about it: Two perspectives on life. In F. A. Huppert, N. Baylis, \& B. Keverne (Eds.), The science of well-being (pp. 285-304). Oxford University Press.

Kahneman, D., \& Thaler, R. H. (2006). Anomalies: Utility maximization and experienced utility. Journal of Economic Perspectives, 20(1), 221-234.

Kahneman, D., Wakker, P. P., \& Sarin, R. (1997). Back to Bentham? Explorations of experienced utility. The Quarterly Journal of Economics, 112(2), 375-406.

Kemp, G. and Santos Silva, J. (2016), Partial effects in fixed effects models, United Kingdom Stata Users' Group Meetings 2016, Stata Users Group.

Lachman, M. E., Lewkowicz, C., Marcus, A., \& Peng, Y. (1994). Images of midlife development among young, middle-aged, and older adults. Journal of Adult Development, 1(4), 201-211.

López Ulloa, B. F. L., Møller, V., \& Sousa-Poza, A. (2013). How does SWB evolve with age? A literature review. Journal of Population Ageing, 6(3), 227-246.

Maddison, A. (2010). Statistics on World Population, GDP and Per Capita GDP, 1-2008 AD. www. ggdc.net/maddison.

Mehlsen, M., Platz, M., \& Fromholt, P. (2003). Life satisfaction across the life course: Evaluations of the most and least satisfying decades of life. The International Journal of Aging and Human Development, 57(3), 217-236.

O'Connor, K. J. (2017). Happiness and welfare state policy around the world. Review of Behavioral Economics, 4(4), 397-420.

Oishi, S., \& Sullivan, H. W. (2006). The predictive value of daily vs retrospective well-being judgments in relationship stability. Journal of Experimental Social Psychology, 42(4), 460-470.

Plagnol, A. C., \& Easterlin, R. A. (2008). Aspirations, attainments, and satisfaction: Life cycle differences between American women and men. Journal of Happiness Studies, 9(4), 601-619.

Van Praag, B. M., and Ferrer-i-Carbonell, A. (2004). Happiness quantified: A satisfaction calculus approach. Oxford University Press.

Prince, M. J., Reischies, F., Beekman, A. T., Fuhrer, R., Jonker, C., Kivela, S. L., \& Copeland, J. R. (1999). Development of the EURO-D scale-a European Union initiative to compare symptoms of depression in 14 European centres. The British Journal of Psychiatry, 174(4), 330-338.

Pudney, S. (2011). Perception and retrospection: The dynamic consistency of responses to survey questions on wellbeing. Journal of Public Economics, 95(3-4), 300-310.

Schröder, M. (2011). Retrospective data collection in the Survey of Health, Ageing and Retirement in Europe. SHARELIFE methodology. Mannheim: Mannheim Research Institute for the Economics of Aging (MEA). 
Schwandt, H. (2016). Unmet aspirations as an explanation for the age U-shape in wellbeing. Journal of Economic Behavior \& Organization, 122, 75-87.

Steptoe, A., Deaton, A., \& Stone, A. A. (2015). Subjective wellbeing, health, and ageing. The Lancet, 385(9968), 640-648.

Stone, A. A., \& Krueger, A. (2018). Understanding SWB. In J. E. Stiglitz, J. P. Fitoussi, \& M. Durand (Eds.), For Good Measure Advancing Research on Well-being Metrics Beyond GDP. OECD.

Stone, A. A., Schwartz, J. E., Broderick, J. E., \& Deaton, A. (2010). A snapshot of the age distribution of psychological well-being in the United States. Proceedings of the National Academy of sciences, 107(22), 9985-9990.

Van Landeghem, B. (2012). A test for the convexity of human well-being over the life cycle: Longitudinal evidence from a 20-year panel. Journal of Economic Behavior \& Organization, 81(2), 571-582.

Winkelmann, R. (2009). Unemployment, social capital, and SWB. Journal of Happiness Studies, 10(4), $421-430$.

Winkelmann, L., \& Winkelmann, R. (1998). Why are the unemployed so unhappy? Evidence from panel data. Economica, 65(257), 1-15.

Wirtz, D., Kruger, J., Scollon, C. N., \& Diener, E. (2003). What to do on spring break? The role of predicted, on-line, and remembered experience in future choice. Psychological Science, 14(5), 520-524.

Wunder, C., Wiencierz, A., Schwarze, J., \& Küchenhoff, H. (2013). Well-being over the life span: Semiparametric evidence from British and German longitudinal data. Review of Economics and Statistics, 95(1), 154-167.

Publisher's Note Springer Nature remains neutral with regard to jurisdictional claims in published maps and institutional affiliations. 